\title{
Individual nanostructure optimization in donor and acceptor phases to achieve efficient quaternary organic solar cells
}

Zhaozhao Bi, Hafiz Bilal Naveed, Xinyu Sui, Qinglian Zhu, Xianbin Xu, Lu Gou, Yanfeng Liu, Ke Zhou, Lei Zhang, Fengling Zhang, Xinfeng Liu and Wei Ma

The self-archived postprint version of this journal article is available at Linköping University Institutional Repository (DiVA):

http://urn.kb.se/resolve?urn=urn:nbn:se:liu:diva-163042

N.B.: When citing this work, cite the original publication.

Bi, Z., Naveed, H. B., Sui, X., Zhu, Q., Xu, X., Gou, Lu, Liu, Y., Zhou, Ke, Zhang, L., Zhang, F., Liu, X., Ma, W., (2019), Individual nanostructure optimization in donor and acceptor phases to achieve efficient quaternary organic solar cells, Nano Energy, 66, 104176.

https://doi.org/10.1016/j.nanoen.2019.104176

Original publication available at:

https://doi.org/10.1016/j.nanoen.2019.104176

Copyright: Elsevier

http://www.elsevier.com/

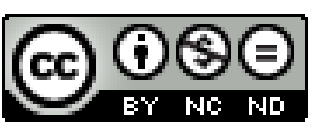




\section{Individual nanostructure optimization in donor and}

\section{acceptor phases to achieve efficient quaternary}

\section{organic solar cells}

Zhaozhao Bi ${ }^{a}$, Hafiz Bilal Naveed ${ }^{a}$, Xinyu Sui ${ }^{b}$, Qinglian Zhu ${ }^{a}$, Xianbin Xu ${ }^{a}$, Lu Gou $^{c}$,

Yanfeng Liu ${ }^{d}$,Ke Zhou ${ }^{a}$, Lei Zhang ${ }^{c}$, Fengling Zhang ${ }^{d}$, Xinfeng Liu ${ }^{b}$,Wei Ma ${ }^{a}{ }^{*}$

a State Key Laboratory for Mechanical Behavior of Materials, Xi'an Jiaotong University, Xi'an, 710049, China

${ }^{b}$ CAS Key Laboratory of Standardization and Measurement for Nanotechnology, CAS Center for Excellence in Nanoscience, National Center for Nanoscience and Technology, Beijing, 100191, China

${ }^{c}$ Shaanxi Province Key Laboratory of Quantum Information and Quantum Optoelectronic Devices, School of Science, Xi'an Jiaotong University, Xi'an, 710049, China

d Biomolecular and Organic Electronics, IFM, Link€oping University, SE-58183, Link€oping, Sweden 
*Corresponding author.

E-mail address: msewma@mail.xjtu.edu.cn (W.Ma)

Keywords: hierarchical morphology optimization, carrier dynamics, quaternary organic solar cells, fullerene, non-fullerene

\section{ABSTRACT}

Fullerene derivative $\left(\mathrm{PC}_{71} \mathrm{BM}\right)$ and high crystallinity molecule (DR3TBDTT) are employed into PTB7-Th:FOIC based organic solar cells (OSCs) to cooperate an individual nanostructure optimized quaternary blend. $\mathrm{PC}_{71} \mathrm{BM}$ functions as molecular adjuster and phase modifier promoting FOIC forming "head-to-head" molecular packing and neutralizing the excessive FOIC crystallites. A multi-scale modified morphology is present thanks to the mixture of FOIC and $\mathrm{PC}_{71} \mathrm{BM}$ while DR3TBDTT disperses into PTB7-Th matrix to reinforce donor's crystallinity and enhance domain purity. Morphology characterization highlights the importance of individually optimized nanostructures for donor and acceptor, which contributes to efficient hole and electron transport toward improved carrier mobilities and suppressed non-geminated recombination. Therefore, a power conversion efficiency of $13.51 \%$ is realized for a quaternary device which is 16\% higher than the binary device (PTB7-Th:FOIC). This work demonstrates that utilizing quaternary strategy for simultaneous optimization of donor and acceptor phases is a feasible way to realize high efficient OSCs.

1. Introduction 
Solution-processed organic solar cells (OSCs) have made great breakthrough in the past two decades $[1,2]$. Persistent design of new photovoltaic materials with innovation in device engineering together driven the power conversion efficiency (PCE) of OSCs exceeding 16\% [37], exhibiting its great potential towards commercial application. Morphology optimization of the bulk-heterojunction, as one of the most important factors for high-performance OSCs, has drawn widely attention of the community [8-12]. Among the various optimization contributions, material design [13-17], solution additive engineering [18,19], processing technique [20-26], and guest component effect [27-34] are considered as the most popular methods. Regarding to the narrow absorption nature of the organic materials, guest component effect that by introducing one or extra active layer materials to control the blend morphology meanwhile broaden the light response region supports an intimate resource for the development of OSCs.

The guest component effects can be divided as ternary, quaternary, and multiple components. In the early stage, the third guest was added into polymer: fullerene system to construct ternary devices. The representative work is adding a wide-bandgap polymer donor (PID2) into PTB7:PCBM blend to construct a cascade charge transport structure with reduced domain size and improved photo absorption, demonstrated by Yu's group [35]. Zhang et al. [36] also proposed an alternative design of cooperating $\mathrm{PTB} 7-\mathrm{Th}: \mathrm{PC}_{71} \mathrm{BM}$ with a high crystalline small molecule to form highly ordered face-on molecular packing. Such contributions on morphology optimization are mainly achieved by adjusting the donor's crystallinity and packing orientation. Afterwards, with the explosive development of non-fullerene acceptors (NFAs), ternary strategies of using various acceptors as guests are utilized to promote the photovoltaic performance of NFAs based OSCs [37,38]. Two structurally similar NFAs are usually used as morphology modifiers to control phase separation and acceptor's crystallinity. Baran et al. [39] 
reported a morphology stable ternary system of P3HT:IDTBR:IDFBR, where IDFBR vitrified the IDTBR dominated phase and hence leads to preservation of the microstructure. Mai et al. [40] observed the backbone ordering could be significantly enhanced by mixing ITIC and ITICTh in the ternary film. Liu et al. [41] proposed a PM6 based ternary system with modified domain size/purity and crystallinity, which is enabled by the synergistic effect of ITCPTC and MeIC. Such ternary designs successfully enhance devices performance through modified morphology, however, only the nanostructures of donors or acceptors is improved with one single guest. That is, the nanostructures optimization of donors and acceptors is not achieved synchronously, hence there is still room regard to further performance enhancement by individually and synchronously optimizing donor and acceptor phases.

Quaternary strategy with another guest offers the possibility to modify both donor and acceptor morphology simultaneously, and some enlightening work has been done. Ko's group [42] constructed a quaternary devices based on $\mathrm{PTB} 7: \mathrm{PC}_{71} \mathrm{BM}$ system via sequentially adding PCDTBT and $\mathrm{PC}_{61} \mathrm{BM}$. PCDTBT mainly increases the photo response and facilitates energy transfer, and $\mathrm{PC}_{61} \mathrm{BM}$ together with $\mathrm{PC}_{71} \mathrm{BM}$ controls the phase growth. This design leads to an enhanced devices performance with long-term stability. Latterly, we developed a "parallel-alloy" morphology model in the PBDB-T:PTB7-Th:ITIC:FOIC quaternary system aiming to modify the FOIC orientation and continuity through the combination of parallel-linked donors (PBDB-T and PTB7-Th) and alloyed acceptors (ITIC and FOIC) [43]. Question should be noted that such designs prefer to optimize acceptor phases primarily but lose the sight of donor phases, which underestimates the superiority of quaternary strategy. Therefore, how to optimize the donor and acceptor phases individually and simultaneously by quaternary design, and how to cooperate the destination-oriented guests for donor and acceptor phases respectively are still unclear. Exploring 
the comprehension regarding such underlying mechanism may contribute to the development of quaternary OSCs.

In this paper, we developed a successful quaternary design route towards individual nanostructure optimization regarding to donor/acceptor and high efficient organic solar cells. Series of high performance quaternary solar cells are fabricated by using a high bandgap and high crystallinity molecule (DR3TBDTT) [44], a mid-bandgap and weak crystallinity polymer donor (PTB7-Th) [45], a narrow-bandgap and high crystallinity molecule acceptor (FOIC) [46] and $\mathrm{PC}_{71} \mathrm{BM}$ to form a cascade aligned energy levels. A multi-scale modified morphology is achieved thanks to $\mathrm{PC}_{71} \mathrm{BM}$ as molecular adjuster promotes FOIC "head-to-head" molecular packing at molecular level and as phase modifier neutralizes the excessive FOIC crystallites at phase domain scale. The PTB7-Th-destined advantage of DR3TBDTT enables further enhanced polymer crystallinity. Such morphological optimizations utilize the individual features of both $\mathrm{PC}_{71} \mathrm{BM}$ and DR3TBDTT and promote the electron and hole transport in FOIC dominated phase and PTB7-Th phase, respectively. This strategy successfully realizes efficient quaternary design in OSCs. As results of efficient carrier transfer, reduced non-geminate recombination, improved charge transport, and promoted charge extraction, an improved PCE of $13.12 \pm 0.19 \%$ with a $V_{\text {oc }}$ of $0.75 \pm 0.01 \mathrm{~V}$, a $J_{\mathrm{sc}}$ of $25.28 \pm 0.48 \mathrm{~mA} \mathrm{~cm}^{-2}$ and a FF of $69.52 \pm 0.78 \%$ is achieved.

2. Results and discussion

2.1. Materials recipe in quaternary blend 

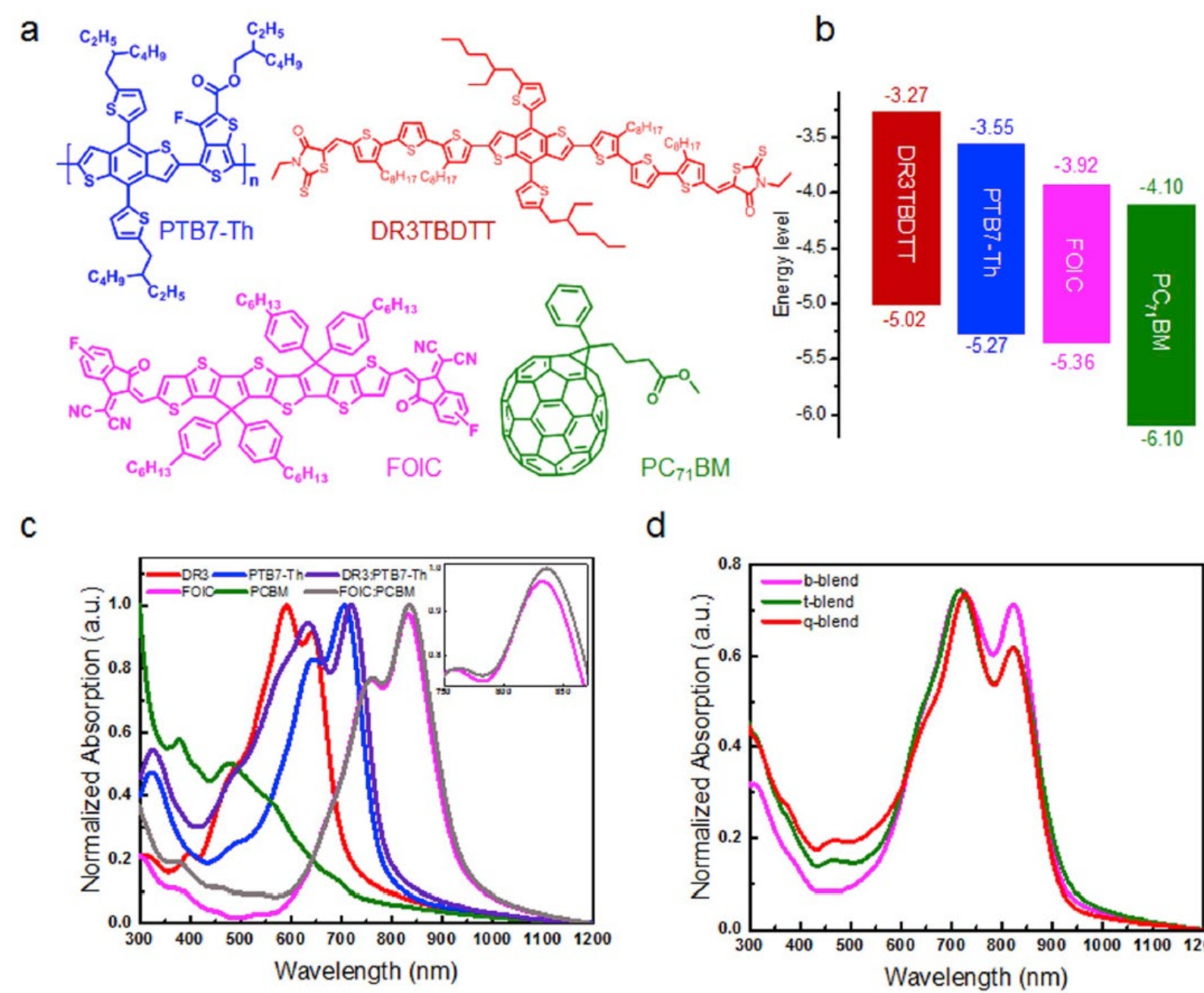

d

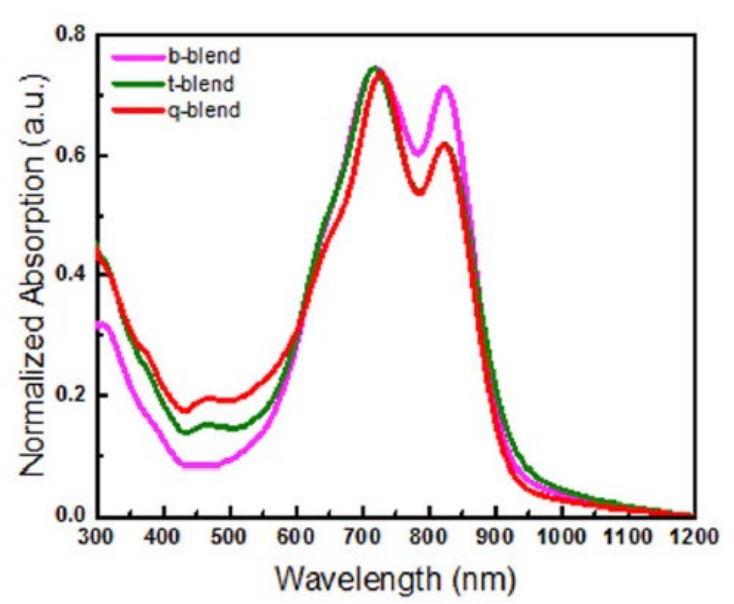

Fig. 1. (a) Chemical structures and (b) energy levels of DR3TBDTT, PTB7-Th, FOIC, and $\mathrm{PC}_{71} \mathrm{BM}$. (c) Normalized UV-vis absorption spectra of the donor and acceptor materials. The inserts are zooming in features of FOIC and FOIC:PC 71 BM. The weight ratio of DR3:PTB7-Th is 0.15:0.85. The DR3 represents DR3TBDTT. (d) Normalized absorption spectra of binary (bblend), ternary (t-blend), and quaternary (q-blend) films. The blend D:A ratio was fixed in 1:1.5, the component of t-blend is $1: 1.2: 0.3$ (PTB7-Th:FOIC:PC ${ }_{71} \mathrm{BM}$ ), the component of q-blend is 0.15:0.85:1.2:0.3 (DR3TBDTT:PTB7-Th:FOIC:PC 71 BM). 
Fig. 1a and b shows the molecular structures and energy levels of the donors and acceptors used in the quaternary device. Those materials were chosen by carefully considering their matching crystallinities, cascade energy levels, and complementary absorption spectra. We found PTB7Th:FOIC blend exhibits excessive and isolated FOIC crystallites in our previous work [43]. Therefore, weak crystallinity fullerene acceptor $\mathrm{PC}_{71} \mathrm{BM}$ was chosen as third component to improve FOIC crystallites forming continuous domains. Meanwhile, $\mathrm{PC}_{71} \mathrm{BM}$ with underlying highest occupied molecular orbital (HOMO) and lowest unoccupied molecular orbital (LUMO) levels can also serve as an electron sink to host and transport electrons effectively [31]. On the other hand, DR3TBDTT has higher crystallinity with upper HOMO and LUMO energy levels than PTB7-Th, thus it may improve donor's crystallinity and contribute to efficient carriers transport. The UV-Vis spectra of the pure components and blend films were probed as shown in Fig. 1c. Those four materials display complementary absorption range of $300-1000 \mathrm{~nm}$ so that the quaternary blend (q-blend) absorption covers the visible and near-infrared (NIR) region of the solar spectrum (Fig. 1d). Interestingly, the considerable shift in the 0-0 transition energy and increase in the 0-0 transition peak of FOIC: $\mathrm{PC}_{71} \mathrm{BM}$ indicate a relative high ordered molecular packing. Considering the negligible absorption of $\mathrm{PC}_{71} \mathrm{BM}$ at $\sim 835 \mathrm{~nm}$, it is surprising to conclude that the crystallinity of FOIC increases due to $\mathrm{PC}_{71} \mathrm{BM}$ [47]. In addition, the absorption spectrum of DR3TBDTT:PTB7-Th blend shows noticeable red shift about $15 \mathrm{~nm}$ than the neat PTB7-Th film. The remarkable shift implies the enhanced conjugated planes packing and increased crystallinity of the polymer [48].

2.2. Performance enhancement in quaternary solar cells 

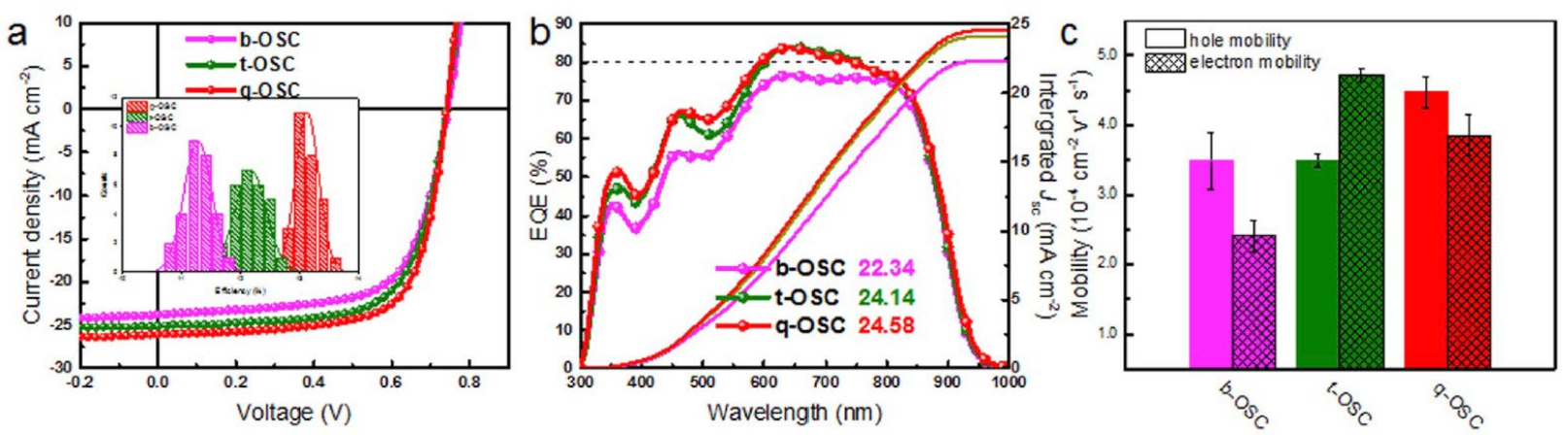

Fig. 2. (a) $J-V$ characteristics of the optimized b-, t-, and q-OSCs. The inserts are histogram of the PCE measurements for over 25 devices based on b-, t-, and q-blends. (b) Corresponding EQE curves and integrated $J_{\text {sc. }}$ (c) Hole mobility and electron mobility.

Table 1 Summarized parameters of the optimized binary, ternary, and quaternary devices under AM 1.5G $100 \mathrm{~mW} \mathrm{~cm}^{-2}$ illumination.

\begin{tabular}{|c|c|c|c|c|c|c|}
\hline & $V_{\mathrm{oc}}{ }^{\mathrm{a}}(\mathrm{V})$ & $J_{\mathrm{sc}}{ }^{\mathrm{a}}\left(\mathrm{mA} \mathrm{cm}^{-2}\right)$ & $\mathrm{FF}^{\mathrm{a}}(\%)$ & $\mathrm{PCE}^{\mathrm{a}}(\%)$ & $\mu_{\mathrm{eb}}\left(\mathrm{cm}^{2} \mathrm{~V}^{-1} \mathrm{~s}^{-1}\right)$ & $\mu \mathrm{hb}\left(\mathrm{cm}^{2} \mathrm{~V}^{-1} \mathrm{~s}^{-1}\right)$ \\
\hline $\mathrm{b}-\mathrm{OSC}$ & $\begin{array}{c}0.74 \pm 0.01 \\
(0.74)\end{array}$ & $\begin{array}{c}23.18 \pm 0.53 \\
(23.77)\end{array}$ & $\begin{array}{c}65.62 \pm 1.08 \\
(66.60)\end{array}$ & $\begin{array}{c}11.27 \pm 0.23 \\
(11.79)\end{array}$ & $\begin{array}{c}(2.41 \pm 0.22) \times \\
10^{-4}\end{array}$ & $\begin{array}{c}(3.49 \pm 0.40) \times \\
10^{-4}\end{array}$ \\
\hline t-OSC & $\begin{array}{c}0.74 \pm 0.01 \\
(0.74)\end{array}$ & $\begin{array}{c}24.34 \pm 0.69 \\
(25.07)\end{array}$ & $\begin{array}{c}67.49 \pm 1.07 \\
(67.86)\end{array}$ & $\begin{array}{c}12.16 \pm 0.26 \\
(12.61)\end{array}$ & $\begin{array}{c}(4.71 \pm 0.09) \times \\
10^{-4}\end{array}$ & $\begin{array}{c}(3.48 \pm 0.10) \times \\
10^{-4}\end{array}$ \\
\hline q-OSC & $\begin{array}{c}0.75 \pm 0.01 \\
(0.74)\end{array}$ & $\begin{array}{c}25.28 \pm 0.48 \\
(26.06)\end{array}$ & $\begin{array}{c}69.52 \pm 0.78 \\
(69.93)\end{array}$ & $\begin{array}{c}13.12 \pm 0.19 \\
(13.51)\end{array}$ & $\begin{array}{c}(3.85 \pm 0.30) \times \\
10^{-4}\end{array}$ & $\begin{array}{c}(4.47 \pm 0.23) \times \\
10^{-4}\end{array}$ \\
\hline
\end{tabular}

a Average values with standard deviation were obtained from at least 25 independent devices and the values in the brackets are the parameters of the best device.

$\mathrm{b}$ The average carrier mobility were calculated from at least 5 devices.

c The component of t-OSC is 1:1.2:0.3 (PTB7-Th:FOIC:PC ${ }_{71} \mathrm{BM}$ ).

$\mathrm{d}$ The component of q-OSC is 0.15:0.85:1.2:0.3 (DR3TBDTT:PTB7-Th:FOIC:PC 71 BM).

In order to evaluate the combination of those four materials, binary (b-OSC, PTB7-Th:FOIC), ternary (t-OSC, PTB7-Th:FOIC:PC 71 BM) and quaternary (q-OSC, DR3TBDTT:PTB7Th:FOIC:PC $71 \mathrm{BM})$ solar cells are fabricated using an inverted device structure. All solutions 
were prepared in $\mathrm{CB}$ solvent with the fixed D:A ratio of 1:1.5. The 1,8-octanedithiol $(0.15 \%)$ was used as solution additive to maintain the immiscibility and restrain the mixing of $\mathrm{PC}_{71} \mathrm{BM}$ and polymer $[49,50]$. The detailed performance parameters are summarized in Fig. 2a and Table 1. The binary devices show a comparable performance of $11.27 \pm 0.23 \%$ with literature $[43,46]$. The high extinction coefficient in the visible-NIR range of FOIC enables high $J_{\text {sc }}$ value of 23.18 $\pm 0.53 \mathrm{~mA} \mathrm{~cm}^{-2}$ [46]. The isolated FOIC dominant phases account for a relatively poor electron transport efficiency and hence lead to a low FF of $65.62 \pm 1.08 \%$ [43]. Afterwards, the optimized t-OSC with $20 \%$ load of $\mathrm{PC}_{71} \mathrm{BM}$ shows improved efficiency of $12.16 \pm 0.26 \%$, and with enhanced photocurrent $\left(24.34 \pm 0.69 \mathrm{~mA} \mathrm{~cm}^{-2}\right)$ and FF $(67.49 \pm 1.07 \%)$, respectively. The presence of $\mathrm{PC}_{71} \mathrm{BM}$ drives the $\mathrm{EQE}$ response to a high level and the maximum quantum efficiency reaches to nearly $84 \%$ (Fig. 2 b), indicating the crucial role of $\mathrm{PC}_{71} \mathrm{BM}$ in facilitating charge collection efficiency in the t-OSC. Moreover, the enhanced FF also points out improved charge transport channels in t-blend, which may relate to a more reasonable phase morphology with the help of $\mathrm{PC}_{71} \mathrm{BM}$. Ternary blends exhibit improved device parameters with $10 \% \sim 30 \%$ $\mathrm{PC}_{71} \mathrm{BM}$ content but inferior performance with over 50\% $\mathrm{PC}_{71} \mathrm{BM}$ loading (Fig. S1 and Table S1 in the supporting information, $\mathrm{SI}$ ). Maintaining a reasonable $\mathrm{PC}_{71} \mathrm{BM} / \mathrm{FOIC}$ ratio is crucial for achieving high device performance, as superfluous fullerene is harmful to light absorption and compact molecular packing, but single FOIC prefers to form excessive and isolated crystallite domains with PTB7-Th. Hence, there should be a superior morphology that integrated the merits of FOIC and $\mathrm{PC}_{71} \mathrm{BM}$, which is reasonable for the improved performance and electronic process in the optimized t-OSC. Hole-only and electron-only devices were fabricated to evaluate the carrier mobility according to space charge limited current (SCLC) model (Fig. 2c and Figs. S2 and SI). The binary blend shows unbalanced charge mobility with low electron mobility ( $\mu \mathrm{e})$ of 
$(2.41 \pm 0.22) \times 10-4 \mathrm{~cm}^{2} \mathrm{~V}^{-1} \mathrm{~S}^{-1}$. Ternary blend, surprisingly, shows increased $\mu \mathrm{e}$ of $(4.71 \pm$ $0.09) \times 10-4 \mathrm{~cm}^{2} \mathrm{~V}^{-1} \mathrm{~S}^{-1}$, which indicates a promoted transport process and is responsible for enhanced FF.

Due to the relative weak conjugate packing of PTB7-Th, a highly crystalline small molecule, DR3TBDTT, is involved in q-OSC after $\mathrm{PC}_{71} \mathrm{BM}$ to reinforce the hole transport. DR3TBDTT does increase $\mu h$ from $(3.48 \pm 0.1) \times 10-4 \mathrm{~cm}^{2} \mathrm{~V}^{-1} \mathrm{~S}^{-1}$ to $(4.47 \pm 0.23) \times 10-4 \mathrm{~cm}^{2} \mathrm{~V}^{-1} \mathrm{~S}^{-1}$ with a little sacrifice of $\mu$ e (Fig. 2c and Fig. S4), and hence yields FF to a high level of $69.52 \pm 0.78 \%$ in the optimized quaternary devices. The $J_{\mathrm{sc}}$ of q-OSC also increases from $24.34 \pm 0.69 \mathrm{~mA} \mathrm{~cm}^{-2}$ to $25.28 \pm 0.48 \mathrm{~mA} \mathrm{~cm}^{-2}$. The light-to-photon conversion capabilities of q- OSCs are discussed via the $\triangle \mathrm{EQE}$ (defined as $\mathrm{EQE}_{\text {quaternary }}-\mathrm{EQE}_{\text {ternary }}$, Fig. $\mathrm{S} 3 \mathrm{~d}$ ) plots [32]. It can be clearly seen the contribution of $15 \%$ DR3TBDTT to photocurrent generation in $450-600 \mathrm{~nm}$ and $800-950 \mathrm{~nm}$ regions, which is mainly due to the absorption of DR3TBDTT and locally facilitated excitons splitting. In addition, the slightly reduced $E_{\text {loss }}$ in $15 \%$ DR3TBDTT blend enables a slightly enhanced $V_{\mathrm{oc}}$ of $0.75 \pm 0.01 \mathrm{~V}$. Finally, three simultaneously increased device parameters ( $V_{\mathrm{oc}}$ $J_{\mathrm{sc}}$ and $\mathrm{FF}$ ) are achieved by the quaternary strategy and lead to $16 \%$ PCE enhancement. Thus, it is reasonable to highlight the successful design of materials recipe with quaternary strategy. The optimized b-, t-, and q-OSC based on various active layer thickness are further evaluated to explore the photovoltaic parameters changes as a function of thickness (Figs. S5 and SI). The qOSC exhibits over $10 \%$ efficiency with about $40 \%$ performance enhancement than b-OSC when the blend film thickness is about $250 \mathrm{~nm}$. The enhanced performance at thick film of q-OSC also indicates the modified blend morphology and carrier mobility.

\subsection{Nanostructure analysis in the blends}


2.3.1. Molecular packing in the blends
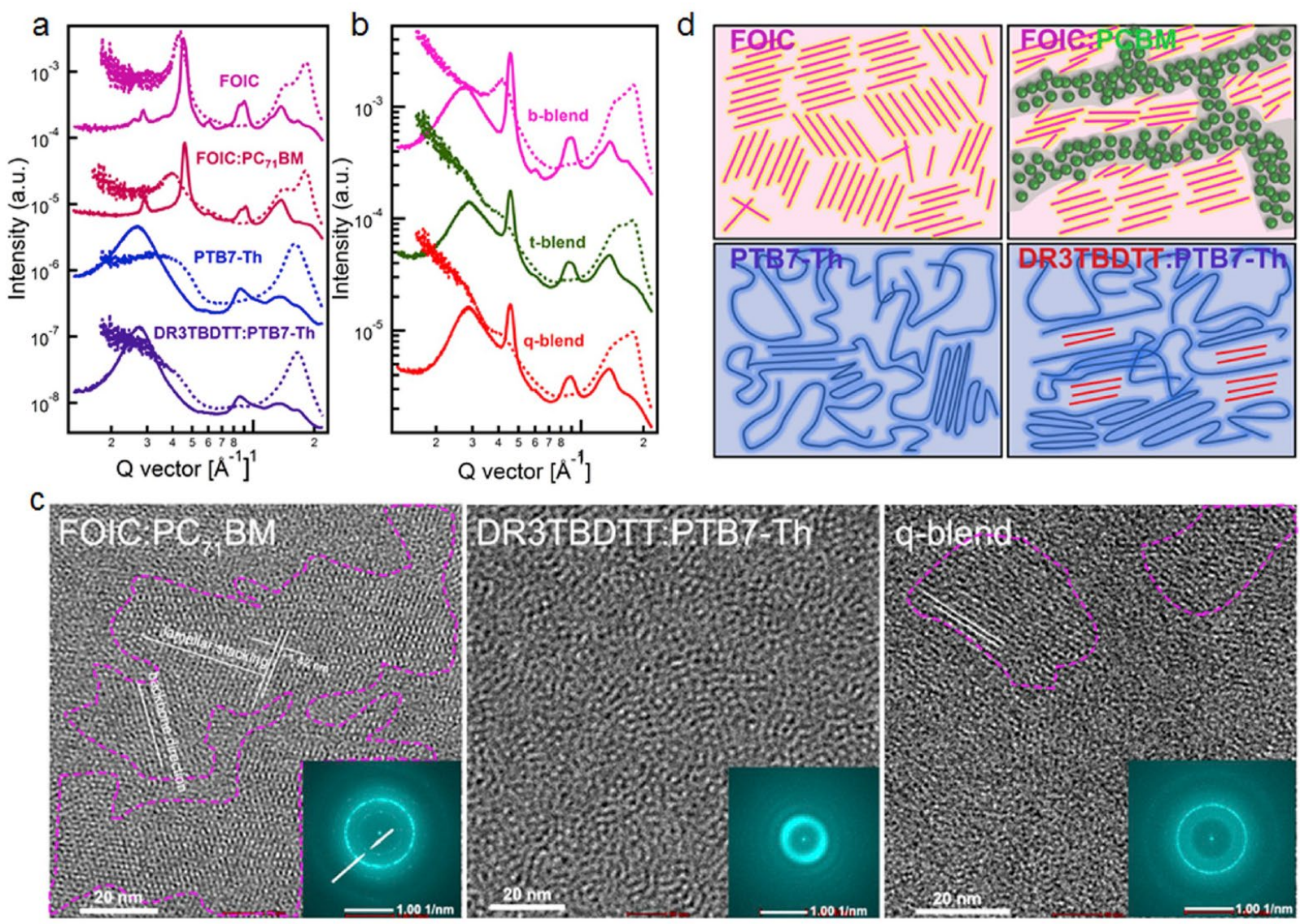

Fig. 3. Characterization of molecular packing. (a) GIWAXS line curves of the neat FOIC, FOIC:PC 71 BM blend, neat PTB7-Th, DR3TBDTT:PTB7-Th blend films, and (b) the b-, t-, and q-blends. The solid lines represent the scattering features along the in-plane direction and the dash lines represent the out-of-plane direction. (c) Cryo- EM images of the FOIC:PC 71 BM blend, DR3TBDTT:PTB7-Th blend, and q-blend films. The inserted turquois figures are the Fourier transformation patterns of the relative real-space inputs. (d) Illustration of the molecular packing in the neat and blend films. 
The impressive device parameters are related to modified active layer morphology, which encourages us to investigate the fine structure of blends in nano-scale by using grazing incident wide angle X-ray scattering (GIWAXS) $[51,52]$ and cryo-electron microscopy (EM). The GIWAXS line curves of PTB7-Th, DR3TBDTT, FOIC, and $\mathrm{PC}_{71} \mathrm{BM}$ in the neat, binary and the optimized ternary and quaternary blends are presented in Fig. 3a and b and Fig. S6a. In comparison to the pristine FOIC, the $(100)$ peak $\left(\mathrm{q} \approx 0.46 \AA^{-1}\right)$ in the out-of-plane $(\mathrm{OoP})$ and inplane (IP) directions is reduced in the FOIC: $\mathrm{PC}_{71} \mathrm{BM}$ blends, while the (001) scattering signal located at $\sim 0.3 \AA^{-1}$ along the IP direction gets strengthened. These changes indicate that $\mathrm{PC}_{71} \mathrm{BM}$ weakens FOIC lamellar packing and simultaneously promotes the "head-to-head" linkage along the FOIC backbone direction [40,53]. Such molecular packing changes may related to the red-shifted UV-vis absorption of FOIC:PC ${ }_{71} \mathrm{BM}$ film shown in Fig. 1c. Cryo-EM techniques are employed to visually probe the enhancement of FOIC (001) peak (Fig. 3c and Fig. S7a). The close packing information of FOIC molecules can be clearly observed, which keeps in good consistent with GWIAXS results. The (001) Fourier transformation ring of FOIC:PC ${ }_{71} \mathrm{BM}$ blend shows higher brightness than that of FOIC neat film, confirming the promoted structure ordering along the backbone direction. When blended FOIC with PTB7-Th, the (001) peak of FOIC is covered up by PTB7-Th lamellar scattering signal to some extent (Fig. 3b), hence we use Gauss mode to track the evolution of FOIC (001) and PTB7-Th (100) peaks (Fig. S8, Tables S4 and SI). The coherence length ( $\mathrm{LC}_{\mathrm{C}}$ ) of FOIC (001) and PTB7-Th (100) peak both increased with $20 \% \mathrm{PC}_{71} \mathrm{BM}$ in the t-blend, along with the decreased FOIC (100) $\mathrm{L}_{\mathrm{C}}$ value. However, the overload of $\mathrm{PC}_{71} \mathrm{BM}$ (over 50\%) may suppress (001) signal of FOIC in the ternary blend as shown in Fig. S9. Therefore, it can be concluded that reasonable content of $\mathrm{PC}_{71} \mathrm{BM}$ can restrain the FOIC lamellar packing and promote the "head-to-head" linkage along the FOIC backbone 
direction at molecular level in the t-blend, and hence contribute to more efficient carriers transport.

In addition, the narrow down (100) and (010) peaks of PTB7-Th in the DR3TBDTT:PTB7-Th blend confirm the increased polymer crystallinity and the condensed polymer packing is responsible for the red-shift absorption of DR3TBDTT:PTB7-Th film. The polymer packing development is also recorded by cryo-EM. By comparing the cryo-EM images of the neat PTB7Th and blend film with DR3TBDTT (Fig. 3c and Fig. S10b), one can clearly see the well miscibility between DR3TBDTT and PTB7-Th with the compact polymer packing in the blend film. Moreover, the increased polymer crystallinity is successfully maintained in the q-blend, along with a slightly reduced FOIC crystallinity, and finally yielding the FF close to $70 \%$ in the q-blend. Such observation confirms the practicable strategy that using DR3TBDTT to purposefully strengthen the PTB7-Th crystallinity and promote hole transport in the quaternary blend.

2.3.2. Phase separation in the blends 


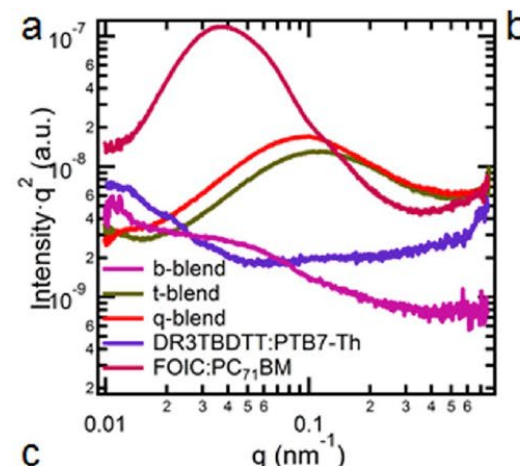

c

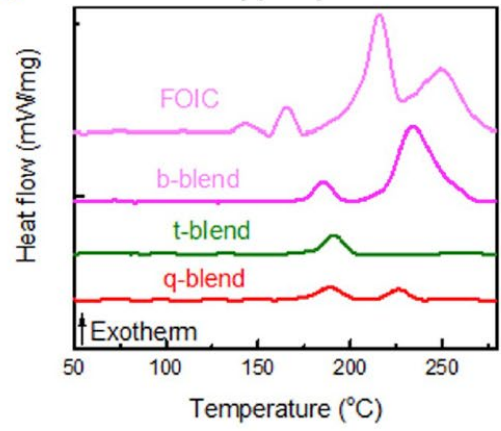

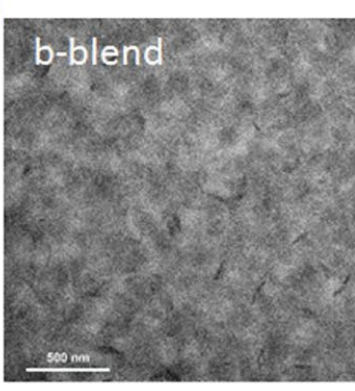

d

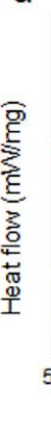

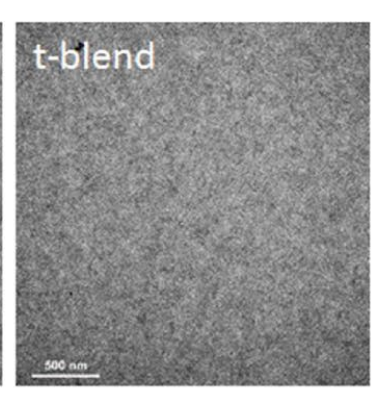

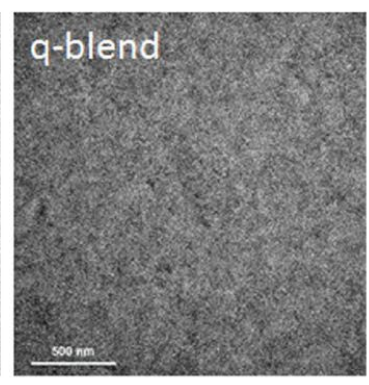

e

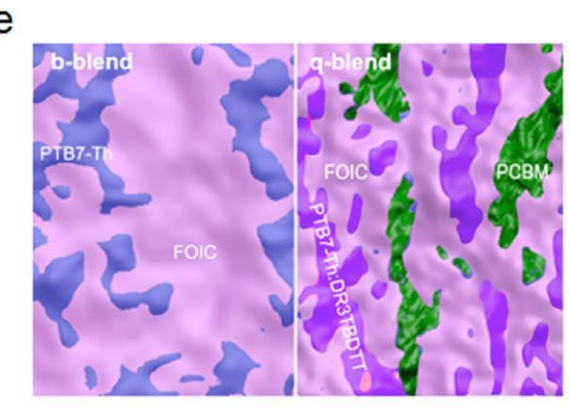

Fig. 4. Characterization of phase separation. (a) Thickness corrected R-SoXS profiles of b-, t-, qblends, DR3TBDTT:PTB7-Th, and FOIC:PC ${ }_{71}$ BM films. (b) TEM images of b-, t-, and q-films. (c) The first DSC heating scans of neat FOIC, b-, t-, and q-blends. (d) DSC scans of the neat DR3TBDTT, neat PTB7-Th, and DR3TBDTT (15\%):PTB7-Th blend. (e) Diagrammatic nanoscale morphology of b- and q-blend.

Resonant soft X-ray scattering (R-SoXS) [54,55] and transmission electron microscopy (TEM) characterizations are followed to figure out the effects of $\mathrm{PC}_{71} \mathrm{BM}$ and DR3TBDTT on the domain level. R-SoXS reveals the dominant length scales of phase separation via enhanced materials contrast at $284.8 \mathrm{eV}$. As shown in Fig. 4a, the b-blend profile shows a scattering peak at $\sim 0.026 \mathrm{~nm}^{-1}$, indicating a phase separation of $242 \mathrm{~nm}$ (domain size of $121 \mathrm{~nm}$ ). The TEM image of b-blend in Fig. 4b also exhibits the supplementary phase information in the real space. 
The large-scale phase separation with discontinuous crystallites of FOIC is similar with our previous observation and is harmful to exciton separation and charge transport [43]. The FOIC:PC ${ }_{71} \mathrm{BM}$ blend is also examined via R-SoXS. FOIC:PC ${ }_{71} \mathrm{BM}$ blend shows obviously bimodal peaks located at $\sim 0.038$ and $\sim 0.10 \mathrm{~nm}^{-1}$, respectively, and the correspond phase separation is about $166 / 62 \mathrm{~nm}$ (domain size: $83 / 31 \mathrm{~nm}$ ). We tend to consider the large-scale phase as FOIC dominant phase cause its high crystallinity and the small-scale separation is probably driven by the miscibility of FOIC and $\mathrm{PC}_{71} \mathrm{BM}$. Surprisingly, the t-blend with $20 \%$ loading of $\mathrm{PC}_{71} \mathrm{BM}$ shows a remarkably reduced domain size of $29 \mathrm{~nm}$, and it is quite similar with the small-scale phase separation of FOIC: $\mathrm{PC}_{71} \mathrm{BM}$. Such observation indicates that phase separation in t-blend is dominated by the FOIC:PC $\mathrm{7}_{71} \mathrm{BM}$ mixture. Besides, the t-blend exhibits a much more homogenous phase in nano-scale (Fig. 4b), indicating the successful strategy of using $\mathrm{PC}_{71} \mathrm{BM}$ to control the phase separation and degrade the excessive crystallite domain of FOIC. Furthermore, comparing to our previous work [43], it should be noted that the superior effects about modifying the blend morphology of $\mathrm{PC}_{71} \mathrm{BM}$ than that of ITIC, ensuring a high efficient performance improvement. The detailed morphology optimization processes of t-OSC with various $\mathrm{PC}_{71} \mathrm{BM}$ ratios revealed by R-SoXS are plotted in Fig. S11a, Supporting Information. FOIC dominant t-blends exhibit decreased domain size than both PTB7-Th:FOIC and PTB7Th: $\mathrm{PC}_{71} \mathrm{BM}$ blends, illustrating the mixture of $\mathrm{FOIC}$ and $\mathrm{PC}_{71} \mathrm{BM}$ together control the phase separation morphology.

On the other hand, the role of DR3TBDTT on phase separation is detected by probing DR3TBDTT:PTB7-Th film via R-SoXS (Fig. 4a). The scattering curve of DR3TBDTT (15\%):PTB7-Th only shows two mass-thickness peaks at super-low $\mathrm{q}\left(\sim 0.01 \mathrm{~nm}^{-1}\right)$ and mid-q $\left(\sim 0.1 \mathrm{~nm}^{-1}\right)$ positions in detectable range (Figs. S11c and SI), indicating that these two materials 
are miscible in such length scale $(10-600 \mathrm{~nm})$. However, the q-blend film shows a low-q shifted scattering curve with higher total scattering intensity than t-blend, which suggests DR3TBDTT enhances the domain purity and enlarges the domain size slightly due to its high crystallinity. The improved domain purity with reasonable domain size is responsible for the increased FF. The blends morphologies with various DR3TBDTT ratio are characterized to further confirm the DR3TBDTT effects on phase separation (Figs. S11b and SI). The scattering features gradually shift to the low-q direction and the purity simultaneously increased with the development of DR3TBDTT content, indicating the phase separation of q-blend can be successfully adjusted due to the high crystallinity nature and well mixed property of DR3TBDTT with PTB7-Th.

Differential scanning calorimetry (DSC) measurements are conducted to detect the role of $\mathrm{PC}_{71} \mathrm{BM}$ and DR3TBDTT in the q-blends. The first heating profiles of FOIC, $\mathrm{b}-\mathrm{t}-$, and q-blend are presented in Fig. 4c. The heat flow scans reveal that the b-, t-, and q-blend with FOIC exhibit exothermal transitions at temperatures above $170^{\circ} \mathrm{C}$, attributed to FOIC cold crystallization. In comparison to the neat FOIC, the cold crystallization transition of FOIC suppressed in all blends cause the PTB7-Th network. In the t-blend, there is a sharp decrease in the crystallization enthalpy change $(\Delta H)$, indicating the depressed FOIC crystalline phase caused by $\mathrm{PC}_{71} \mathrm{BM}$ at high temperature. This observation further confirm the feasible strategy of using $\mathrm{PC}_{71} \mathrm{BM}$ to suppress the FOIC crystalline domain. In addition, the neat DR3TBDTT exhibits unique melting peaks during the heating and cooling cycles, and it is clearly seen that there is no DR3TBDTT characteristic peaks from heating and cooling cycles of DR3TBDTT:PTB7-Th blend (Fig. 3d). These results mean that the DR3TBDTT is not present as an individual phase in the DR3TBDTT (15\%):PTB7-Th film and q-blend [36]. Notably, the cold crystallization transition peak locates at $226^{\circ} \mathrm{C}$ in the q-blend, attributed to DR3TBDTT cold crystalline transformation. We speculate 
the DR3TBDTT cold crystallization barrier in the polymer matrix is reduced due to the vitrifaction of acceptors in quaternary system. Considering above analysis, it declares that $\mathrm{PC}_{71} \mathrm{BM}$ mainly dissolves in the FOIC domains for enhanced "head-to-head" packing and suppressed lamellar packing of FOIC at molecular level (illustrated schematically in Fig. 3d) while promotes homogeneous phase separation and reduced domain size at phase scale (illustrated in Fig. 4e). On the other hand, DR3TBDTT molecular mixes in the PTB7-Th matrix towards improved crystallinity with enlarged domain purity and phase separation properly. The individually modified acceptor and donor phases are responsible for the enhanced devices performance.

\subsection{Carrier dynamics investigation in the devices}
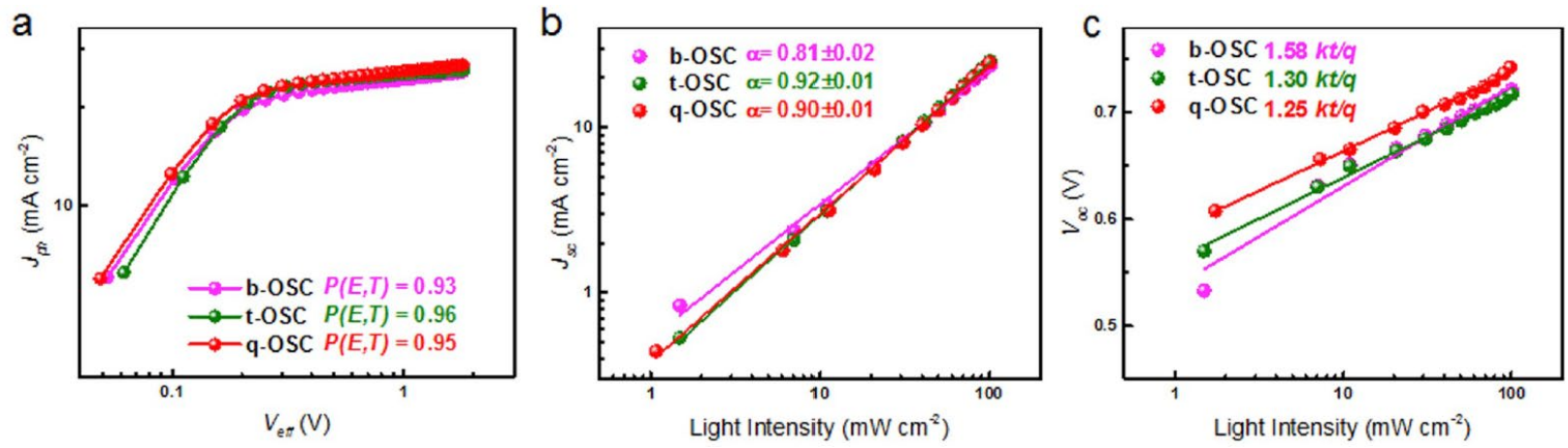

Fig. 5. (a) Photocurrent density versus effective voltage. (b) Measured $J_{\text {sc }}$ versus light intensity. (c) $V_{\text {oc }}$ versus light intensity for b-, t-, and q-OSCs.

The hierarchically modified morphology sets the foundation for superior photoelectric process in devices. To gain insight into exciton dissociation and charge extraction, the dependence of photocurrent density $\left(J_{\mathrm{ph}}\right)$ and effective voltage $\left(V_{\text {eff }}\right)$ was studied. $J_{\mathrm{ph}}$ is defined as $J_{\mathrm{ph}}=J_{\mathrm{L}}-J_{\mathrm{D}}$, where $J_{\mathrm{L}}$ and $J_{\mathrm{D}}$ are the current density under illumination and in the dark, respectively [56]. $V_{\text {eff }}$ 
is determined as $V_{\text {eff }}=V_{0}-V$, where $V_{0}$ represents the voltage at which $J_{\text {ph }}$ is zero, and $V$ represents the applied voltage bias [57]. As shown in Fig. 5a, the $J_{\mathrm{ph}}$ of the b-, t-, and q-OSCs all reaches to its saturation $\left(J_{\text {sat }}\right)$ at high reverse voltage, with $J_{\text {sat }}$ values of 25.61, 26.00, and 26.95 $\mathrm{mA} \mathrm{cm}{ }^{-2}$, respectively. The larger $J_{\text {sat }}$ values of t- and q-devices suggest enlarged excitons generation [35]. Furthermore, the values of $J_{\mathrm{ph}} / J_{\mathrm{sat}}$ under the short circuit condition can be used to describe the charge dissociation probability $P(E, T)$ [58]. The calculated $P(E, T)$ values for b-, t, and q-devices are $0.93,0.96$, and 0.95 , respectively, confirming the ternary and quaternary strategies facilitate the exciton dissociation and charge collection efficiencies. Afterwards, nongeminate recombination was investigated through analyzing the dependence of $J_{\mathrm{sc}}$ and $V_{\mathrm{oc}}$ on light intensity $\left(P_{\text {light }}\right)($ Fig. $5 \mathrm{~b}$ and c). The power law dependence can be used to describe the correlation between $J_{\mathrm{sc}}$ and $P_{\text {light }}$ as $J_{\mathrm{sc}} \propto P_{\text {light }}^{\alpha}$, where a close to unity value of $\alpha$ means a weak bimolecular recombination in blends [59]. The t- and q-blends show higher $\alpha$ values of 0.92 and 0.90 , respectively, indicating reduced bimolecular recombination. This should be related to the optimized nano-scale morphology. Correspondingly, binary blend shows an $\alpha$ of 0.81 , which means severe bimolecular loss and an inferior morphology is responsible for that. The slope of $V_{\text {oc }}$ versus the natural logarithm of $P_{\text {light }}$ can be used to distinguish whether trap-assisted monomolecular or bimolecular recombination dominants the non-geminate mechanism. Namely, a close to $k \mathrm{~T} / q$ value means bimolecular recombination is dominant, and a slope of $2 k \mathrm{~T} / q$ means trap-assisted recombination is dominant [56,60]. The b-, t-, and q-OSCs give the slopes of 1.58 , 1.30 , and $1.25 \mathrm{kT} / q$, respectively. Therefore, it is reasonable to deduce that $\mathrm{PC}_{71} \mathrm{BM}$ and DR3TBDTT can remedy the traps in the primary b-blend and consequentially lead to gradually reduced trap-assisted monomolecular recombination. 

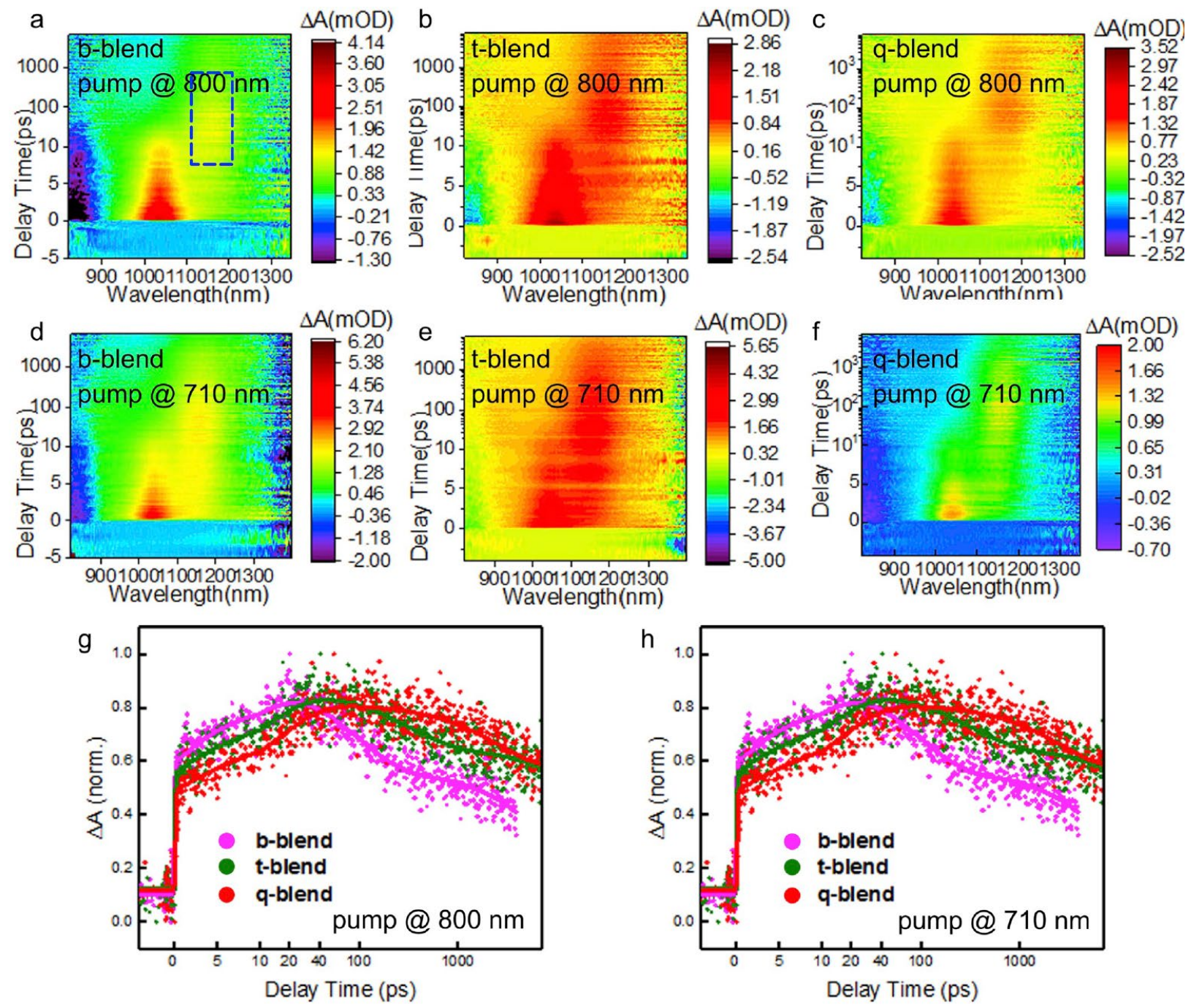

Fig. 6. TAS features of the b-, t-, and q-blends excited at $800 \mathrm{~nm}(\mathrm{a}-\mathrm{c})$ and $710 \mathrm{~nm}(\mathrm{~d}-\mathrm{f})$, respectively. The $800 \mathrm{~nm}$ laser was chose to motivate FOIC domains. The $710 \mathrm{~nm}$ laser was selected to mainly excite PTB7-Th polymer. The rectangle area indicates the light-introduced polar absorption features. Time evolutions of polaron signal $1160 \mathrm{~nm}$ for the $\mathrm{b}-$, $\mathrm{t}-$, and q-blends with pump wavelength of $800 \mathrm{~nm}(\mathrm{~g})$ and $710 \mathrm{~nm}(\mathrm{~h})$, respectively. 
Transient absorption spectroscopy (TAS) was adopted to further investigate the charge carrier dynamics in donor and acceptor phases. Neat film features for FOIC, PTB7-Th, and their blends with $\mathrm{PC}_{71} \mathrm{BM}$ and DR3TBDTT are shown in Fig. S12 (SI). Pump wavelength of $800 \mathrm{~nm}$ was chosen here to selectively excited the FOIC phases with an eye on the hole transfer process to PTB7-Th phases. We stretched our depiction further for t- and q-blends using similar excitation. Here, the broad absorption peak at $1160 \mathrm{~nm}$ is assigned to polaron absorption (Fig. 6a-c), consistent with earlier report [61]. Time evolution of polaron signal has shown in Fig. 6g. Quantified life time for polaron growth ( $\mathrm{1} 1)$ and decay ( $\mathrm{\tau} 2)$ were presented in Table S5 (SI). Time constant $\tau 1$ and $\tau 2$ are the respective representation of hole transfer and decay of electron in FOIC phases [62-64]. Here, we notice that $\tau 1$ remains consistent for all the blends with

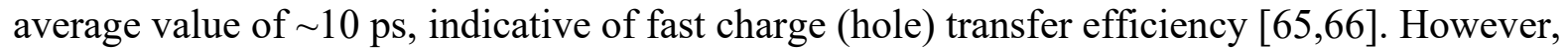
enhanced value of $\tau 2$ from $b$-blend to $t$ - and q-blends depicts improved charge transport. With $800 \mathrm{~nm}$ excitation of blend films here, we report an improved electron transport efficiency with optimized acceptor nanostructures without sacrificing ultrafast hole transfer from FOIC to donor domains in t-blend (and q-blend) as a result of $\mathrm{PC}_{71} \mathrm{BM}$ (and DR3TBDTT) incorporation. Extended life time of polarons with the addition of $\mathrm{PC}_{71} \mathrm{BM}$ (t-blend) and trap-assisted recombination towards more efficient electron transport in acceptor phases of $\mathrm{t}$ - and q-blends.

On the other side, the b-, t- and q-blend films were excited at $710 \mathrm{~nm}$ and polaron absorption peaks were obtained at $1160 \mathrm{~nm}$. With a higher energy excitation as compared to earlier description, we got a stronger absorption signal due to the presence of both electrons and holes in donor and acceptor phases. Time evolution of polaron signal has shown in Fig. 6h. Quantified life time for polaron growth ( $\tau 1)$ and decay ( $\tau 2)$ were presented in Table S6, Supporting Information. Differently from previous depiction, a consistent growth time ( $\tau 1)$ with decreased 
decay time ( $\tau 2)$ were obtained in the t-blend. We have already established improved electron transport in FOIC phases via efficient (trap-free) acceptor phases in t-blends. Here, a depleted polaron life time in the t-blend is assigned to unfavorable donor nanostructures and inefficient hole transport in PTB7-Th phases. Hence, DR3TBDTT was used as the fourth component and an enhanced life time ( $\mathrm{\tau} 2$ ) was recorded for q-blend (as compared to b-blend). By using TAS analysis, we confirmed optimized acceptor (donor) phases resulting in improved electron (hole) transport in respective $\mathrm{t}$ - and q-blends. In summary, incorporation of $\mathrm{PC}_{71} \mathrm{BM}$ and DR3TBDTT in PTB7-Th:FOIC blend results in fast growth of polarons and superior life time towards improved charge transport efficiency via reduced non-geminate recombination. We report enhanced $\mathrm{EQE}\left(J_{\mathrm{sc}}\right)$ and FF values with selective optimization of acceptor and donor nanostructures towards the realization of superior t- and q-OSCs.

\subsection{Voltage losses in quaternary solar cells}

The energy loss during the exciton dissociation and carrier recombination processes are also studied. Electroluminescence (EL) and Fourier transform photocurrent spectroscopy (FTPS$\mathrm{EQE})$ measurements were conducted to track the incurred energy loss during charge generation. As shown in Fig. S13 (SI), the b-, t-, and q-OSCs give quite closed EL emission peaks, indicating the similar excitons dissociation/ charge transfer process at donor/acceptor interface [9,67]. Namely, such charge generation processes mainly exist at PTB7-Th/FOIC interface even in the ternary and quaternary devices, which signifies a controllable morphology that $\mathrm{PC}_{71} \mathrm{BM}$ and DR3TBDTT get into FOIC and PTB7-Th dominated phase, respectively. In addition, following the $E_{\mathrm{CT}}$ deduced from the FTPS-EQE curves, the calculated driving force losses $(\Delta E 2)$ are $0.17,0.18$, and $0.14 \mathrm{eV}$ for the b-, t-, and q-OSCs, respectively. Considering the comparable 
charge recombination energy losses of b-, t-, and q-OSCs, the reduced $\triangle E 2$ is responsible for a higher $V_{\mathrm{oc}}$ in the quaternary devices (Table S7).

\subsection{Stability improvement in quaternary devices}

The impacts of the quaternary strategy on the device stability are evaluated by storing the devices into the nitrogen full-filled glovebox. As shown in Fig. S14 (SI), the b-OSC loses its $10 \%$ PCE after storing for about $600 \mathrm{~h}$ ( $\sim 25$ days). However, it takes $1440 \mathrm{~h}$ ( $\sim 60$ days) and 1600 $\mathrm{h}$ ( $\sim 66$ days) for the $\mathrm{t}-$ and q-OSC reaches to its $90 \%$ performance, respectively. Such prolonged decay time of the t- and q- OSC is 2.4 and 2.6 times longer than that of b-OSC, showing the greatly improved stability caused by $\mathrm{PC}_{71} \mathrm{BM}$. It is speculated that the $\mathrm{PC}_{71} \mathrm{BM}$ with higher glass transition temperature may act as plasticizer to suppress the molecular thermal vibration. In addition, it should be noted that the photocurrent loss of the q-OSC is faster than that of t-OSC, but the FF loss is quite slower. It is assumed that the q-blend might tend to form large domain size with higher domain purity during the storage due to the high crystallinity nature and well mixed feature with PTB7-Th of DR3TBDTT.

\section{Conclusion}

This work proposed an efficient quaternary design to improve the acceptor and donor phases purposefully in the bulk-heterojunction film. The individually modified quaternary blend morphology is obtained by selecting appropriate material recipe with suitable crystallinities, matched miscibility, cascade energy levels and complementary absorption. Consequently, the excessive and isolated FOIC crystallites in the PTB7-Th:FOIC blend are suppressed by a weak crystallinity molecule: $\mathrm{PC}_{71} \mathrm{BM}$, and the FOIC molecular packing refines to "head-to-head" linkage along the backbone direction due to the proper intermolecular interactions between 
$\mathrm{PC}_{71} \mathrm{BM}$ and FOIC. Meanwhile, the ternary blend presents a reasonable phase separation scale thanks to the FOIC: $\mathrm{PC}_{71} \mathrm{BM}$ mixture. Such beneficial morphology evolution illustrates the unique advantage of $\mathrm{PC}_{71} \mathrm{BM}$ as the guest modifier. Afterwards, DR3TBDTT is cooperated aiming to increase the donor's crystallinity due to its high crystallinity nature and well-mixed property with PTB7-Th, with improved domain purity and without sacrificing the finely adjusted domain size. This hierarchically modified morphology enables facilitated excitons dissociation, controlled carriers transfer, enhanced carrier transport and restrained recombination, which accounts for $16 \%$ PCE enhancement for quaternary OSCs with over $13.5 \%$ power conversion efficiency. Our successful quaternary strategy of using $\mathrm{PC}_{71} \mathrm{BM}$ and DR3TBDTT to individually modify the bulk heterojunction morphology of PTB7-Th:FOIC based devices provides an intimate resource for constructing high-efficient OSCs and guides the further investigation of quaternary systems.

\section{ACKNOWLEDGEMENTS}

The authorship acknowledges the support from Ministry of science and technology (No. 2016YFA0200700), NSFC (21704082, 21875182, 21534003), China Postdoctoral Science Foundation (2017M623162), 111 project 2.0 (BP2018008). Cryo-EM data were collected at the Instrument Analysis Center of Xi'an Jiaotong University. X-ray data were acquired at beamlines 7.3.3 and 11.0.1.2 at the Advanced Light Source, which is supported by the Director, Office of Science, Office of Basic Energy Sciences, of the U.S. Department of Energy under Contract No. DE-AC02-05CH11231. The authors thank Chenhui Zhu at beamline 7.3.3, and Cheng Wang at beamline 11.0.1.2 for assistance with data acquisition.

\section{REFERENCES}


[1] A. Wadsworth, M. Moser, A. Marks, M.S. Little, N. Gasparini, C.J. Brabec, D. Baran, I. McCulloch, Chem. Soc. Rev. 48 (2019) 1596.

[2] O. Ingan€as, Adv. Mater. 30 (2018) 1800388.

[3] L. Meng, Y. Zhang, X. Wan, C. Li, X. Zhang, Y. Wang, X. Ke, Z. Xiao, L. Ding, R. Xia, H.-L. Yip, Y. Cao, Y. Chen, Science 361 (2018) 1094.

[4] X. Xu, K. Feng, Z. Bi, W. Ma, G. Zhang, Q. Peng, Adv. Mater. 31 (2019) 1901872.

[5] Y. Cui, H. Yao, J. Zhang, T. Zhang, Y. Wang, L. Hong, K. Xian, B. Xu, S. Zhang,

J. Peng, Z. Wei, F. Gao, J. Hou, Nat. Commun. 10 (2019) 2515.

[6] B. Fan, D. Zhang, M. Li, W. Zhong, Z. Zeng, L. Ying, F. Huang, Y. Cao, Sci. China Chem. $62(2019) 746$.

[7] Q. An, X. Ma, J. Gao, F. Zhang, Sci. Bull. 64 (2019) 504.

[8] C. Poelking, M. Tietze, C. Elschner, S. Olthof, D. Hertel, B. Baumeier, F. Wuerthner, K. Meerholz, K. Leo, D. Andrienko, Nat. Mater. 14 (2015) 434.

[9] N.A. Ran, S. Roland, J.A. Love, V. Savikhin, C.J. Takacs, Y.-T. Fu, H. Li, V. Coropceanu, X. Liu, J.-L. Bredas, G.C. Bazan, M.F. Toney, D. Neher, T.-Q. Nguyen, Nat. Commun. 8 (2017) 79.

[10] L. Ye, H. Hu, M. Ghasemi, T. Wang, B.A. Collins, J.-H. Kim, K. Jiang, J. H. Carpenter, H. Li, Z. Li, T. McAfee, J. Zhao, X. Chen, J.L.Y. Lai, T. Ma, J.-L. Bredas, H. Yan, H. Ade, Nat. Mater. 17 (2018) 253. 
[11] H. Lee, C. Park, D.H. Sin, J.H. Park, K. Cho, Adv. Mater. 30 (2018) 1800453.

[12] F. Zhao, C. Wang, X. Zhan, Adv. Energy Mater. 8 (2018) 1703147.

[13] P. Cheng, G. Li, X. Zhan, Y. Yang, Nat. Photonics 12 (2018) 131.

[14] J. Hou, O. Inganas, R.H. Friend, F. Gao, Nat. Mater. 17 (2018) 119.

[15] J. Zhang, H.S. Tan, X. Guo, A. Facchetti, H. Yan, Nat. Energy 3 (2018) 720.

[16] H. Yao, Y. Cui, D. Qian, C.S. Ponseca Jr., A. Honarfar, Y. Xu, J. Xin, Z. Chen, L. Hong, B. Gao, R. Yu, Y. Zu, W. Ma, P. Chabera, T. Pullerits, A. Yartsev, F. Gao, J. Hou, J. Am. Chem. Soc. 141 (2019) 7743.

[17] Q. An, W. Gao, F. Zhang, J. Wang, M. Zhang, K. Wu, X. Ma, Z. Hu, C. Jiao, C. Yang, J. Mater. Chem. A 6 (2018) 2468.

[18] J. Chen, Z. Bi, X. Xu, Q. Zhang, S. Yang, S. Guo, H. Yan, W. You, W. Ma, Adv. Sci. 6 (2019) 1801560.

[19] R. Yu, H. Yao, L. Hong, Y. Qin, J. Zhu, Y. Cui, S. Li, J. Hou, Nat. Commun. 9 (2018) 4645.

[20] Y. Diao, Y. Zhou, T. Kurosawa, L. Shaw, C. Wang, S. Park, Y. Guo, J.A. Reinspach, K. Gu, X. Gu, B.C.K. Tee, C. Pang, H. Yan, D. Zhao, M.F. Toney, S.C.B. Mannsfeld, Z. Bao, Nat. Commun. 6 (2015) 7955.

[21] X. Gu, L. Shaw, K. Gu, M.F. Toney, Z. Bao, Nat. Commun. 9 (2018) 534.

[22] L. Zhang, B. Lin, B. Hu, X. Xu, W. Ma, Adv. Mater. 30 (2018) 1800343. 
[23] W. Li, M. Chen, J. Cai, E.L.K. Spooner, H. Zhang, R.S. Gurney, D. Liu, Z. Xiao, D. G. Lidzey, L. Ding, T. Wang, Joule 3 (2019) 819.

[24] W. Li, M. Chen, Z. Zhang, J. Cai, H. Zhang, R.S. Gurney, D. Liu, J. Yu, W. Tang, T. Wang, Adv. Funct. Mater. 29 (2018) 1807662.

[25] J. Zhao, Y. Li, G. Yang, K. Jiang, H. Lin, H. Ade, W. Ma, H. Yan, Nat. Energy 1 (2016) 15027.

[26] Z. Li, L. Ying, P. Zhu, W. Zhong, N. Li, F. Liu, F. Huang, Y. Cao, Energy Environ. Sci. $12(2019) 157$.

[27] Q. An, F. Zhang, J. Zhang, W. Tang, Z. Deng, B. Hu, Energy Environ. Sci. 9 (2016) 281.

[28] N. Gasparini, A. Salleo, I. McCulloch, D. Baran, Nat. Rev. Mater. 4 (2019) 229.

[29] H.B. Naveed, W. Ma, Joule 2 (2018) 621.

[30] L. Nian, Y. Kan, H. Wang, K. Gao, B. Xu, Q. Rong, R. Wang, J. Wang, F. Liu, J. Chen, G. Zhou, T.P. Russell, A.K.Y. Jen, Energy Environ. Sci. 11 (2018) 3392.

[31] Z. Zhou, S. Xu, J. Song, Y. Jin, Q. Yue, Y. Qian, F. Liu, F. Zhang, X. Zhu, Nat. Energy 3 (2018) 952.

[32] X. Song, N. Gasparini, M.M. Nahid, S.H.K. Paleti, J.-L. Wang, H. Ade, D. Baran, Joule 3 (2019) 846.

[33] X. Xu, Z. Bi, W. Ma, Z. Wang, W.C.H. Choy, W. Wu, G. Zhang, Y. Li, Q. Peng, Adv. Mater. 29 (2017) 1704271. 
[34] Q. An, J. Wang, F. Zhang, Nano Energy 60 (2019) 768.

[35] L. Lu, T. Xu, W. Chen, E.S. Landry, L. Yu, Nat. Photonics 8 (2014) 716.

[36] J. Zhang, Y. Zhang, J. Fang, K. Lu, Z. Wang, W. Ma, Z. Wei, J. Am. Chem. Soc. 137 (2015) 8176.

[37] X. Ma, M. Luo, W. Gao, J. Yuan, Q. An, M. Zhang, Z. Hu, J. Gao, J. Wang, Y. Zou, C. Yang, F. Zhang, J. Mater. Chem. A 7 (2019) 7843.

[38] M. Zhang, Z. Xiao, W. Gao, Q. Liu, K. Jin, W. Wang, Y. Mi, Q. An, X. Ma, X. Liu, C. Yang, L. Ding, F. Zhang, Adv. Energy Mater. 8 (2018) 1801968.

[39] D. Baran, R.S. Ashraf, D.A. Hanifi, M. Abdelsamie, N. Gasparini, J.A. Rohr, S. Holliday, A. Wadsworth, S. Lockett, M. Neophytou, C.J.M. Emmott, J. Nelson, C. J. Brabec, A. Amassian, A. Salleo, T. Kirchartz, J.R. Durrant, I. McCulloch, Nat. Mater. 16 (2017) 363.

[40] J. Mai, Y. Xiao, G. Zhou, J. Wang, J. Zhu, N. Zhao, X. Zhan, X. Lu, Adv. Mater. 30 (2018) 1802888.

[41] T. Liu, Z. Luo, Q. Fan, G. Zhang, L. Zhang, W. Gao, X. Guo, W. Ma, M. Zhang, C. Yang, Y. Li, H. Yan, Energy Environ. Sci. 11 (2018) 3275.

[42] M. Nam, M. Cha, H.H. Lee, K. Hur, K.-T. Lee, J. Yoo, I.K. Han, S.J. Kwon, D.-H. Ko Nat. Commun. 8 (2017) 14068.

[43] Z. Bi, Q. Zhu, X. Xu, H.B. Naveed, X. Sui, J. Xin, L. Zhang, T. Li, K. Zhou, X. Liu, X. Zhan, W. Ma, Adv. Funct. Mater. 29 (2019) 1806804. 
[44] J. Zhou, Y. Zuo, X. Wan, G. Long, Q. Zhang, W. Ni, Y. Liu, Z. Li, G. He, C. Li, B. Kan, M. Li, Y. Chen, J. Am. Chem. Soc. 135 (2013) 8484.

[45] S.-H. Liao, H.-J. Jhuo, Y.-S. Cheng, S.-A. Chen, Adv. Mater. 25 (2013) 4766.

[46] T. Li, S. Dai, Z. Ke, L. Yang, J. Wang, C. Yan, W. Ma, X. Zhan, Adv. Mater. 30 (2018) 1705969.

[47] Y. Liu, J. Zhao, Z. Li, C. Mu, W. Ma, H. Hu, K. Jiang, H. Lin, H. Ade, H. Yan, Nat. Commun. 5 (2014) 5293.

[48] G. Zhang, K. Zhang, Q. Yin, X.-F. Jiang, Z. Wang, J. Xin, W. Ma, H. Yan, F. Huang, Y. Cao, J. Am. Chem. Soc. 139 (2017) 2387.

[49] J.K. Lee, W.L. Ma, C.J. Brabec, J. Yuen, J.S. Moon, J.Y. Kim, K. Lee, G.C. Bazan, A. J. Heeger, J. Am. Chem. Soc. 130 (2008) 3619.

[50] C. McDowell, M. Abdelsamie, M.F. Toney, G.C. Bazan, Adv. Mater. 30 (2018) 1707114.

[51] J. Rivnay, S.C.B. Mannsfeld, C.E. Miller, A. Salleo, M.F. Toney, Chem. Rev. 112 (2012) 5488.

[52] A. Hexemer, W. Bras, J. Glossinger, E. Schaible, E. Gann, R. Kirian, A. MacDowell, M. Church, B. Rude, H. Padmore, J. Phys. Conf. Ser. 247 (2010), 012007.

[53] G. Han, Y. Guo, X. Song, Y. Wang, Y. Yi, J. Mater. Chem. C 5 (2017) 4852.

[54] E. Gann, A.T. Young, B.A. Collins, H. Yan, J. Nasiatka, H.A. Padmore, H. Ade, A. Hexemer, C. Wang, Rev. Sci. Instrum. 83 (2012), 045110. 
[55] B.A. Collins, Z. Li, J.R. Tumbleston, E. Gann, C.R. McNeill, H. Ade, Adv. Energy

Mater. 3 (2013) 65.

[56] S.R. Cowan, A. Roy, A.J. Heeger, Phys. Rev. B 82 (2010) 245207.

[57] S.R. Cowan, R.A. Street, S. Cho, A.J. Heeger, Phys. Rev. B 83 (2011), 035205.

[58] V.D. Mihailetchi, L.J. Koster, J.C. Hummelen, P.W. Blom, Phys. Rev. Lett. 93 (2004) 216601.

[59] P. Schilinsky, C. Waldauf, C.J. Brabec, Appl. Phys. Lett. 81 (2002) 3885.

[60] M.M. Mandoc, F.B. Kooistra, J.C. Hummelen, B. de Boer, P.W.M. Blom, Appl. Phys. Lett. 91 (2007) 263505.

[61] S. Dai, S. Chandrabose, J. Xin, T. Li, K. Chen, P. Xue, K. Liu, K. Zhou, W. Ma, J. M. Hodgkiss, X. Zhan, J. Mater. Chem. A 7 (2019) 2268.

[62] L. Zhan, S. Li, H. Zhang, F. Gao, T.K. Lau, X. Lu, D. Sun, P. Wang, M. Shi, C.Z. Li, H. Chen, Adv. Sci. 5 (2018) 1800755.

[63] D. Baran, N. Gasparini, A. Wadsworth, C.H. Tan, N. Wehbe, X. Song, Z. Hamid, W. Zhang, M. Neophytou, T. Kirchartz, C.J. Brabec, J.R. Durrant, I. McCulloch, Nat. Commun. 9 (2018) 2059.

[64] Y. Li, L. Zhong, B. Gautam, H.-J. Bin, J.-D. Lin, F.-P. Wu, Z. Zhang, Z.-Q. Jiang, Z.-G. Zhang, K. Gundogdu, Y. Li, L.-S. Liao, Energy Environ. Sci. 10 (2017) 1610.

[65] A.J. Barker, K. Chen, J.M. Hodgkiss, J. Am. Chem. Soc. 136 (2014) 12018. 
[66] S. Gelinas, A. Rao, A. Kumar, S.L. Smith, A.W. Chin, J. Clark, T.S. van der Poll, G. C. Bazan, R.H. Friend, Science 343 (2014) 512.

[67] S. Ullbrich, J. Benduhn, X. Jia, V.C. Nikolis, K. Tvingstedt, F. Piersimoni, S. Roland, Y. Liu, J. Wu, A. Fischer, D. Neher, S. Reineke, D. Spoltore, K. Vandewal, Nat. Mater. 18 (2019) 459. 
Supporting Information

\section{Individual Nanostructure Optimization in Donor and Acceptor}

\section{Phases to Achieve Efficient Quaternary Organic Solar Cells}

Zhaozhao Bi ${ }^{\mathrm{a}}$, Hafiz Bilal Naveed ${ }^{\mathrm{a}}$, Xinyu Sui ${ }^{\mathrm{b}}$, Qinglian Zhu ${ }^{\mathrm{a}}$, Xianbin $\mathrm{Xu}^{\mathrm{a}}$, Lu Gou ${ }^{\mathrm{c}}$, Yanfeng Liu ${ }^{\mathrm{d}}$, Ke Zhou ${ }^{\mathrm{a}}$, Lei Zhang ${ }^{\mathrm{c}}$, Fengling Zhang ${ }^{\mathrm{d}}$, Xinfeng Liu ${ }^{\mathrm{b}}$, Wei Ma ${ }^{\mathrm{a} *}$

${ }^{\text {a }}$ State Key Laboratory for Mechanical Behavior of Materials, Xi'an Jiaotong University, Xi'an 710049, China

${ }^{\mathrm{b}}$ CAS Key Laboratory of Standardization and Measurement for Nanotechnology, CAS Center for Excellence in Nanoscience, National Center for Nanoscience and Technology, Beijing 100191, China

${ }^{c}$ Shaanxi Province Key Laboratory of Quantum Information and Quantum

Optoelectronic Devices, School of Science, Xi'an Jiaotong University, Xi'an 710049, China

${ }^{\mathrm{d}}$ Biomolecular and Organic Electronics, IFM, Linköping University, SE-58183, Linköping, Sweden

*Corresponding author.

E-mail address: msewma@mail.xjtu.edu.cn (W. Ma)

Keywords: hierarchical morphology optimization, carrier dynamics, quaternary organic solar cells, fullerene, non-fullerene 


\section{Measurements and characterizations}

Materials: PTB7-Th (Solarmer Materials Inc.), DR3TBDTT (1-Material Inc.), $\mathrm{PC}_{71} \mathrm{BM}$ (Solenne BV Inc.) were used as received without further purification. The FOIC was synthesized according to the reported literatures.[1]

Device Fabrication and measurement: The organic photovoltaic devices were fabricated based on the protocol optimized for the PTB7-Th:FOIC binary devices. An inverted structure $\left(\mathrm{ITO} / \mathrm{ZnO} /\right.$ active layer $\left./ \mathrm{MoO}_{3} / \mathrm{Al}\right)$ was utilized to evaluate the device performance. The ITO-coated substrates were sequentially cleaned by ultrasonication in detergent-water mixture, deionized water, acetone, and isopropanol (each step for $20 \mathrm{~min})$. The cleaned glass substrates were further exposure by oxygen plasma for 20 min to eliminate remaining organic matters. The $\mathrm{ZnO}$ precursor (zinc acetate dihydrate, dissolved in 2-methoxyethanol with ethanolamine) was spin-coated on the prepared ITO glasses with a thickness of $\approx 30 \mathrm{~nm}$ and baked at $200{ }^{\circ} \mathrm{C}$ for $60 \mathrm{~min}$. Then the glasses were transferred to a nitrogen glove box, where the solutions with different donors and acceptors were spun onto the $\mathrm{ZnO}$ surface to get $100 \mathrm{~nm}$ thick films via varied spin-coating rates. The solution with a fixed D:A ratio of 1:1.5 was prepared in chlorobenzene solvent with $0.15 \%$ 1,8-octanedithiol, stirred overnight on a $50{ }^{\circ} \mathrm{C}$ hotplate. Finally, $10 \mathrm{~nm} \mathrm{MoO}_{3}$ and $100 \mathrm{~nm}$ Al were sequentially deposited on the active layer at a vacuum level of $<1 \times 10^{-4} \mathrm{~Pa}$. Typical devices area $\left(0.04 \mathrm{~cm}^{2}\right)$ was defined by a metal mask with aligned aperture. The $J-V$ characteristics were carried 
out using an AAA solar simulator (SS-F5-3A, Enlitech) in glove box. The radiative intensity (AM 1.5G spectrum, $100 \mathrm{~mW} \mathrm{~cm}^{-2}$ ) was calibrated by a standard silicon cell with a KG5 filter (calibrated by Enli Tech. Optoelectronic Calibration Lab.) and a Keighley 2400 source meter unit. $J-V$ curves were measured in the forward direction from -0.5 to $1.0 \mathrm{~V}$, with a scan step of $20 \mathrm{mV}$ and a dwell time of $1 \mathrm{~ms}$. The EQE data were collected using the integrated spectral response system (QE-R3018, Enlitech).

Cryo-EM \& TEM: The Cryo-EM specimens were prepared as follow. In brief, samples were floated on a glow-discharged holey carbon film-coated copper grid (QUANTIFOIL ${ }^{\circledR}$ R 2/2, Electron Microscopy Sciences). Grids were blotted manually using a custom-built manual plunger at room temperature. Samples were blotted for 4-5 s with Whatman No.1 filter paper immediately before plunge freezing in liquid ethane cooled by liquid nitrogen. The flash-frozen grids were transferred into liquid nitrogen for storage. Cryo-EM samples were examined using a FEI Talos F200C TEM operating at $200 \mathrm{KV}$ high tension at $-178{ }^{\circ} \mathrm{C}$ in low dose mode. A Gatan 626 cryo-holder was used. The micrographs were acquired with a high-sensitivity $4 \mathrm{~K} \times 4 \mathrm{~K}$ pixel FEI CETA CMOS camera under the magnifications of $13500 \times-120 \mathrm{k} \times$. TEM images were obtained using the same microscope.

Hole and electron mobility measurement: Hole-only devices were fabricated using the architectures of ITO/PEDOT:PSS/Active layer/MoO $/$ Al. Electron-only devices were fabricated using the structures of $\mathrm{ITO} / \mathrm{ZnO} /$ Active layer/Ca/Al. The mobilities were 
calculated using space charge limited current (SCLC) model by fitting the current density-voltage curves and calculated by the equation:[2, 3]

$$
J=9 \varepsilon_{0} \varepsilon_{\mathrm{r}} \mu\left(V_{a p p l}-V_{b i}-V_{s}\right)^{2} / 8 L^{3}
$$

Where $J$ is current density, $\varepsilon_{0}$ is the permittivity of free space, $\varepsilon_{\mathrm{r}}$ is the relative permittivity of the material (assumed to 3), $\mu$ is hole mobility or electron mobility, $V_{a p p l}$ is applied voltage, $V_{b i}$ is the built-in voltage, $V_{s}$ is the voltage drop from the substrate's series resistance $\left(V_{s}=\mathrm{IR}\right)$ and $\mathrm{L}$ is the thickness of film.

Grazing incidence wide-angle X-ray scattering (GIWAXS): The GIWAXS measurements were performed at beamline 7.3.3[4] at the Advanced Light Source. Samples were prepared on Si substrates using identical blend solutions as those used in devices. The $10 \mathrm{keV} \mathrm{X}$-ray beam was incident at a grazing angle of $0.12^{\circ}-0.16^{\circ}$, selected to maximize the scattering intensity from the samples. The scattered x-rays were detected using a Dectris Pilatus 2M photon counting detector.

Resonant Soft X-ray Scattering (RSoXS): The R-SoXS transmission measurements were performed at beamline 11.0.1.2[5] at the Advanced Light Source (ALS). Samples for R-SoXS measurements were prepared on a PEDOT:PSS modified Si substrate under the same conditions as those used for device fabrication, and then transferred by floating in water to a $1.5 \mathrm{~mm} \times 1.5 \mathrm{~mm}, 100 \mathrm{~nm}$ thick $\mathrm{Si}_{3} \mathrm{~N}_{4}$ membrane supported by a $5 \mathrm{~mm} \times 5 \mathrm{~mm}, 200 \mu \mathrm{m}$ thick Si frame (Norcada Inc.). 2-D scattering patterns were collected on an in-vacuum CCD camera (Princeton Instrument PI-MTE). 
The sample detector distance was calibrated from diffraction peaks of a triblock copolymer poly(isoprene-b-styrene-b-2-vinyl pyridine), which has a known spacing of $391 \AA$. The beam size at the sample is approximately $100 \mu \mathrm{m}$ by $200 \mu \mathrm{m}$.

Differential scanning calorimetry (DSC) measurement: DSC experiments were carried out with a NETZSCH DSC214 instrument at a heating rate of $15{ }^{\circ} \mathrm{C} \mathrm{min}{ }^{-1}$ under nitrogen atmosphere. Samples were prepared by drop-casting the neat or blend materials from chlorobenzene solution into the prepared glass sheets. After the totally evaporation of solvent in air, the completely dried samples were collected into $\mathrm{Al}$ crucibles by scraping the materials from the glass sheets.

Transition absorption spectra measurements (TAS): TAS measurement was performed using a commercial fs-TAS system, i.e., HELIOS (Ultrafast Systems). The $800 \mathrm{~nm}$ pulses from a Coherent Astrella regenerative amplifier (80 fs, $1 \mathrm{kHz}, 10$ $\mathrm{mJ} /$ pulse), seeded by a Coherent Vitara-s oscillator (35 fs, $80 \mathrm{MHz}$ ), was used to pump an optical parametric amplifier (Coherent, OperA Solo) to generate excitation pulse at $400 \mathrm{~nm}$. The pump beam was chopped at $500 \mathrm{~Hz}$ with pump fluence at $\sim 5$ $\mu \mathrm{J} / \mathrm{cm}^{2}$, while a small fraction of the $800 \mathrm{~nm}$ output from the Astralla was fed to a sapphire crystal in the HELIOS for generating the white light continuum (WLC). A $780 \mathrm{~nm}$ short pass filter (SPF) is typically used to suppress the residual 800 from the WLC generation. The system has an ultimate temporal resolution of $\sim 140$ fs. The principle of TA spectra can be expressed as: $\Delta \mathrm{A}(\lambda)=-\log \left(\mathrm{I}(\lambda)_{\text {pump-on }} / \mathrm{I}(\lambda)_{\text {pump-off }}\right)$, 
where $\Delta \mathrm{A}(\lambda)$ is the absorption difference spectrum, i.e., the absorption spectrum of the excited sample minus the absorption spectrum of the ground-state sample: $\mathrm{I}(\lambda)_{\text {pump-on }}$ and $\mathrm{I}(\lambda)_{\text {pump-off }}$ are the intensity of the probe pulse with pump on or pump off, respectively. The lifetimes were fitted using a Gaussian response function convoluted with a triple exponential decay function:

$$
\Delta \mathrm{A}(\mathrm{t})=\mathrm{A}_{1} \exp \left(-\mathrm{t} / \tau_{1}\right)+\mathrm{A}_{2} \exp \left(-\mathrm{t} / \tau_{2}\right)+\mathrm{A}_{3} \exp \left(-\mathrm{t} / \tau_{3}\right)
$$

Electroluminescence measurement: An external current/voltage source was employed to provide an external electric field to the blended solar cells. The electroluminescence emissions were recorded with an Andor spectrometer.

FTPS-EQE measurement: The FTPS-EQE was measured with a Vertex 70 from Bruker Optics, which was equipped with a quartz tungsten halogen lamp, quartz beam-splitter and external detector option. A low-noise current amplifier (SR570) was used to amplify the photocurrent produced under illumination of the solar cells, with light modulated by the Fourier transform infrared spectroscope (FTIR). The output voltage of the current amplifier was fed back into the external detector port of the FTIR to use the FTIR software to collect the photocurrent spectra.

$\mathrm{EQE}_{\mathrm{EL}}$ measurement: The $\mathrm{EQE}_{\mathrm{EL}}$ was recorded with an in-house-built system comprising a Hamamatsu silicon photodiode 1010B, Keithley 2400 source meter (for 
supplying voltages and recording injected currents), and Keithley 485 picoammeter (for measuring the emitted light intensity).

\section{Supplementary Information}

\subsection{Supplementary Figure}
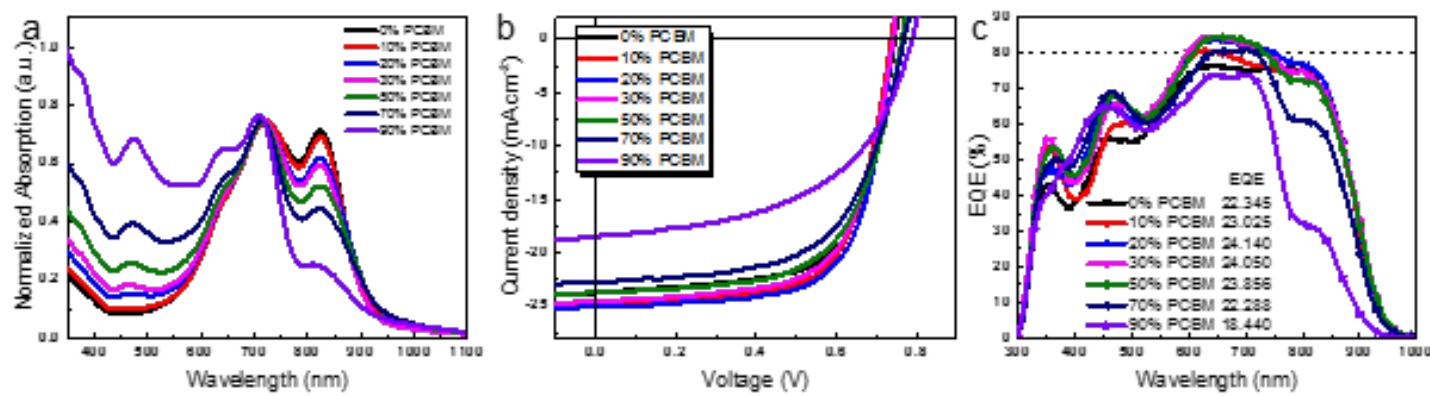

Figure S1. (a) The normalized UV-vis absorption spectra, (b) $J-V$ curves, and (c) EQE responses of ternary devices with various PCBM contents.
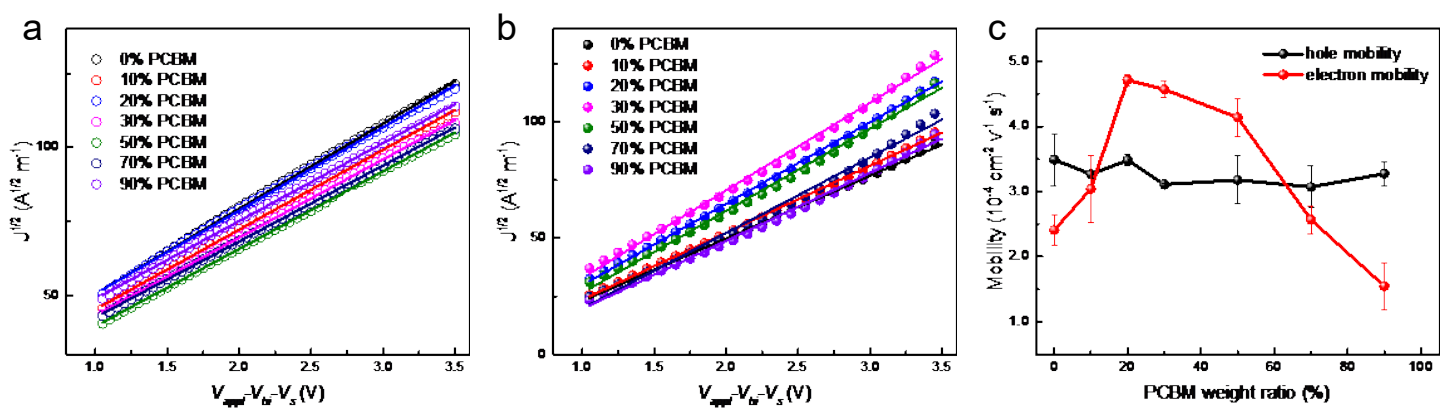

Figure S2. The $J^{1 / 2}-V$ characteristics of the hole-only (a) and electron-only (b) devices based on ternary blends. The lines present linear fitting results. (c) The summarized component dependence of carrier mobility variations of ternary devices. 

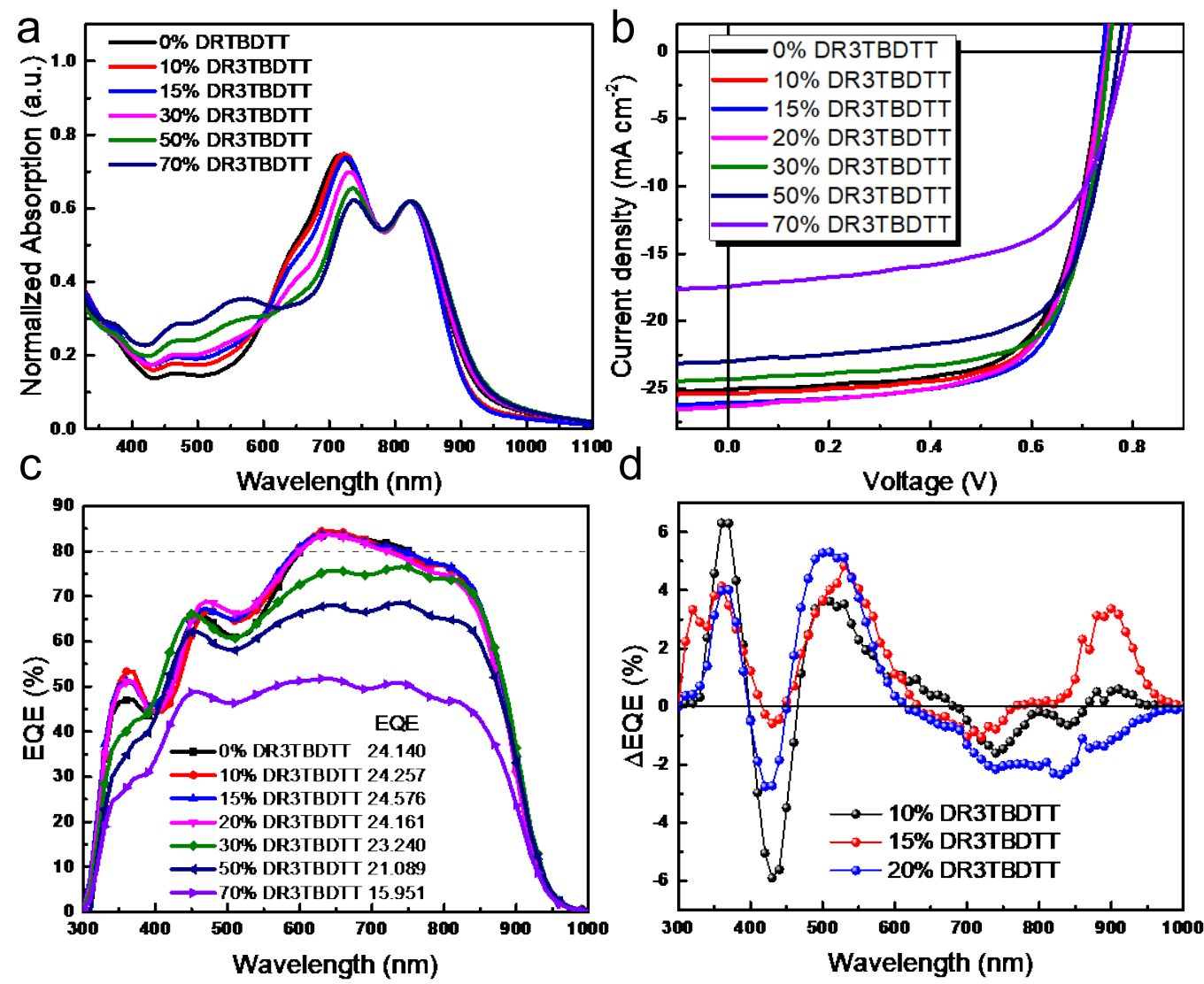

Figure S3. (a) The normalized UV-vis absorption spectra, (b) $J-V$ curves, and (c) EQE responses of the quaternary devices with various DR3TBDTT contents. (d) Calculated $\triangle \mathrm{EQE}$ curves of quaternary blends with representative DR3TBDTT contents.
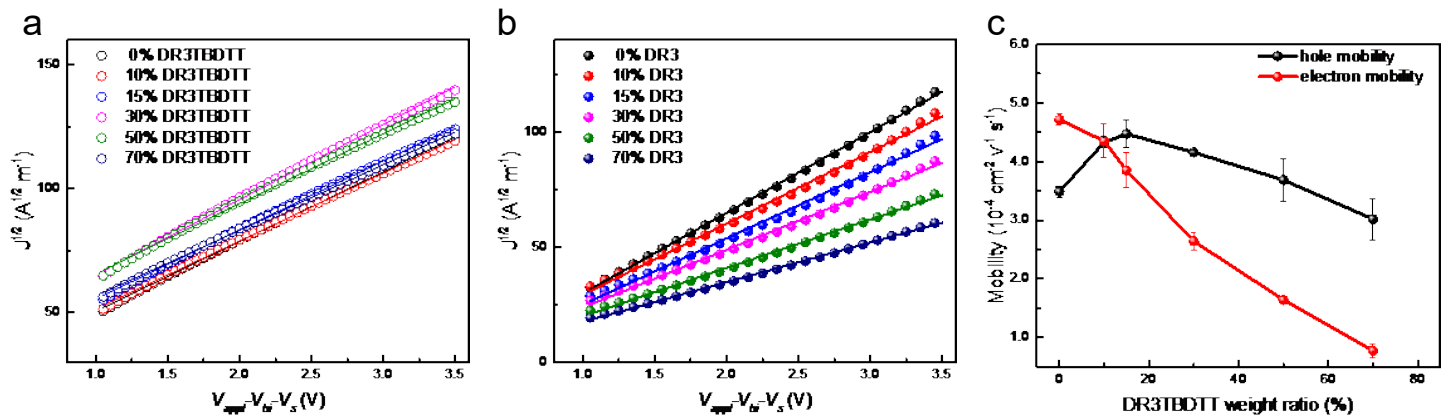

Figure S4. The $J^{1 / 2}-V$ characteristics of the hole-only (a) and electron-only (b) devices based on the quaternary blends. The lines present linear fitting results. (c) The summarized component dependence of carrier mobility variations of quaternary devices. 

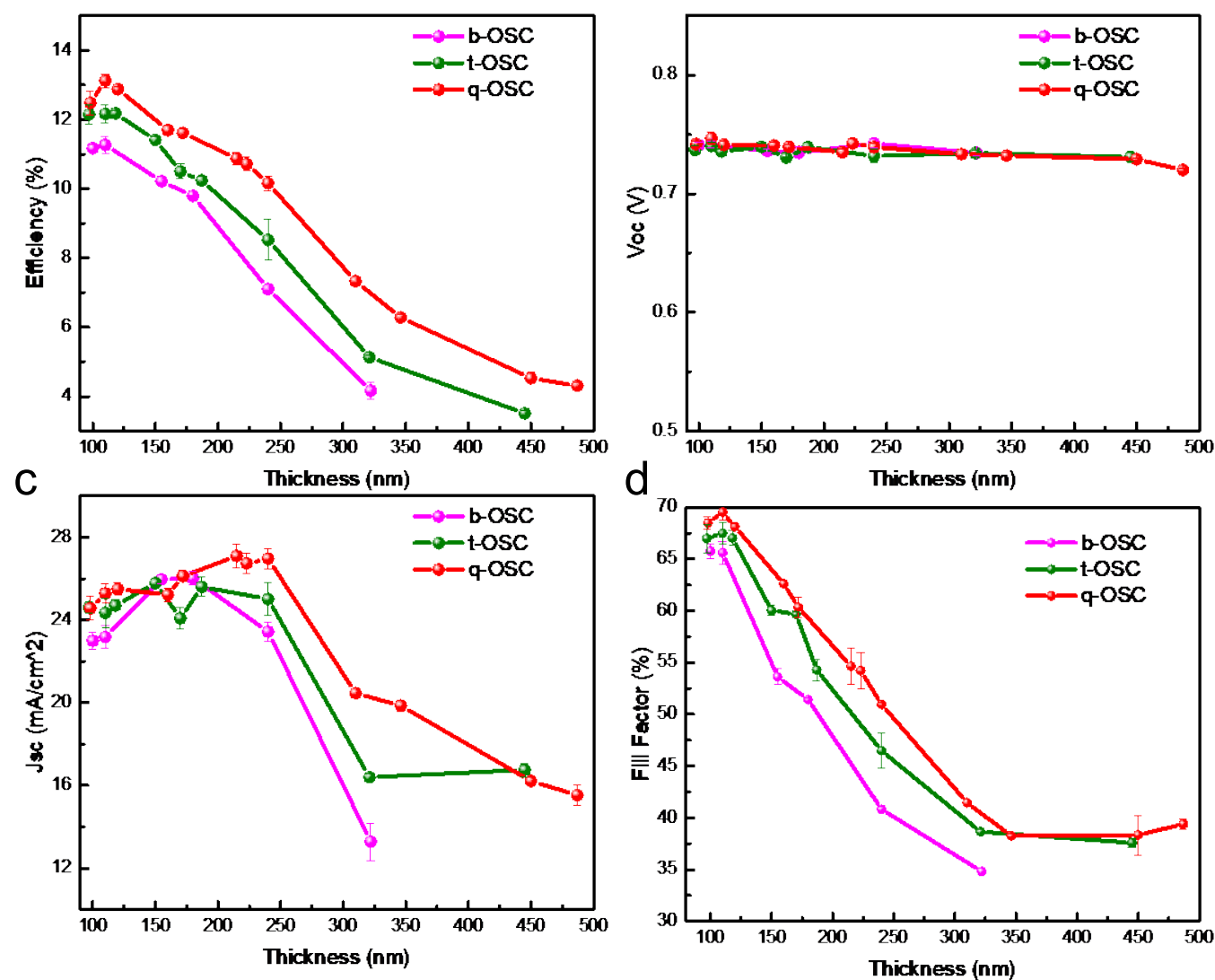

Figure S5. The thickness dependence of (a) PCE, (b) $V_{\text {oc, }}$, (c) $J_{\text {sc }}$, and (d) FF of the optimized b-, t-, and q-OSCs.
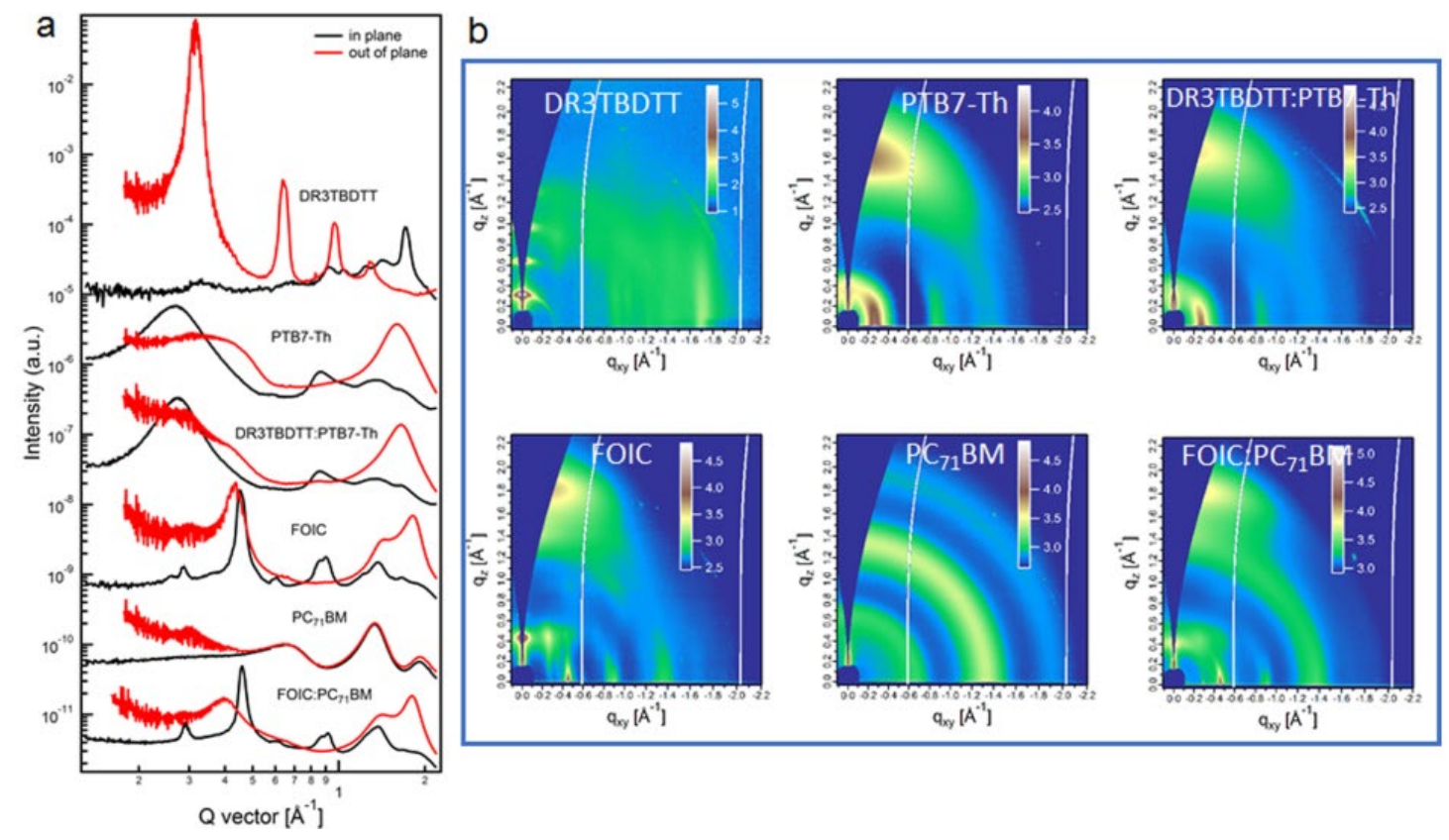
Figure S6. (a) The GIWAXS line curves and (b) 2D GIWAXS patterns of the neat DR3TBDTT, PTB7-Th, FOIC, PC 71 BM films and the DR3TBDTT:PTB7-Th, FOIC:PC ${ }_{71} \mathrm{BM}$ blends
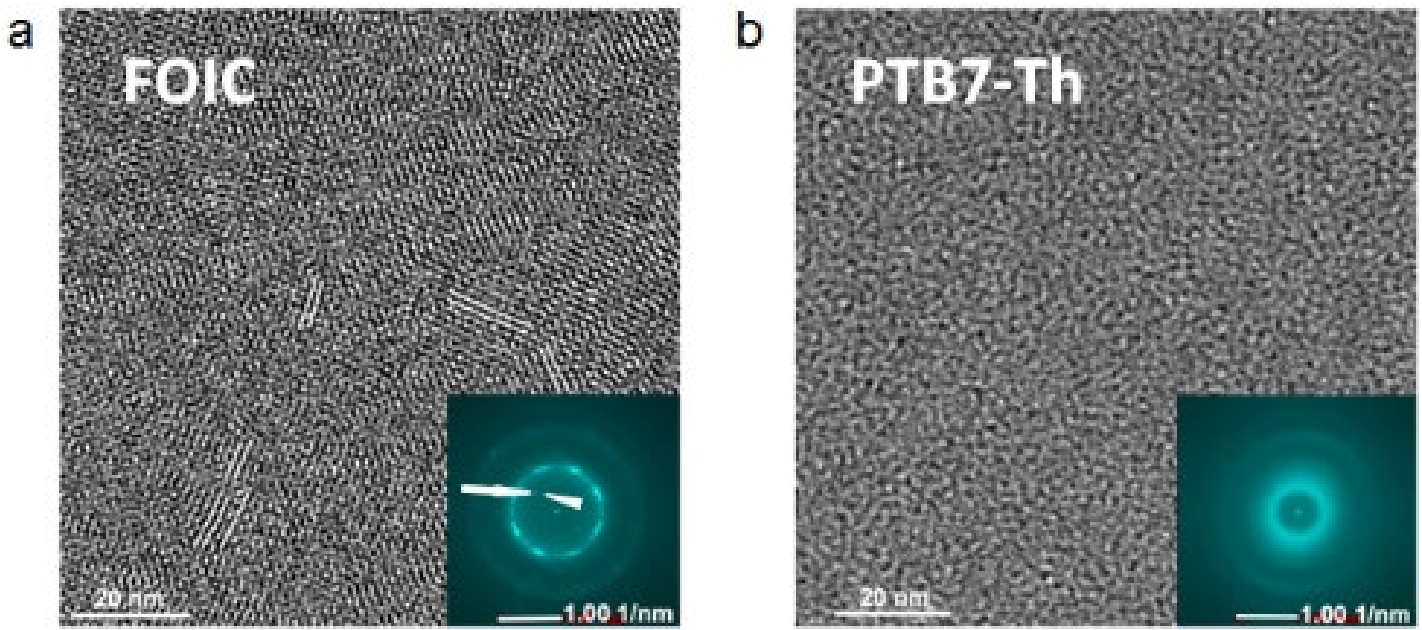

Figure S7. Cryo-EM images of the neat FOIC and neat PTB7-Th films. The inserted turquois figures are the Fourier transformation patterns of the relative real-space inputs.

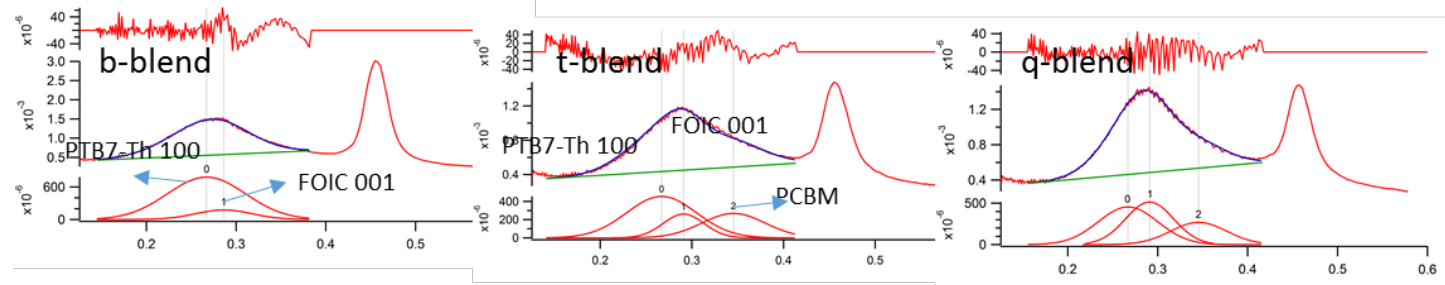

Figure S8. The GIWAXS fitting results of the b-, $t-$, and q-blends along the in-plane direction. 

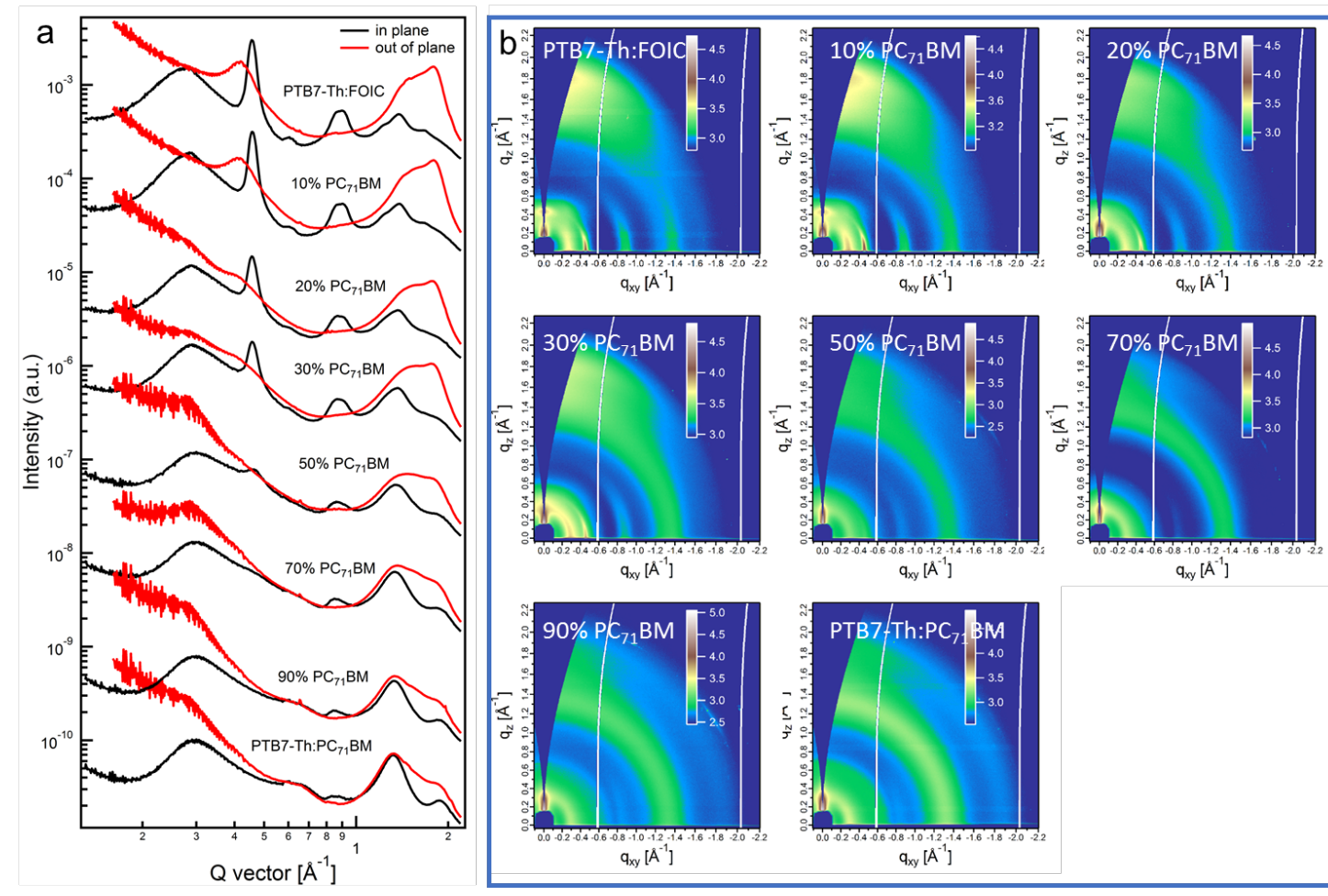

Figure S9. (a) The GIWAXS line curves and (b) 2D GIWAXS patterns of the ternary blends with various PCBM ratios. 

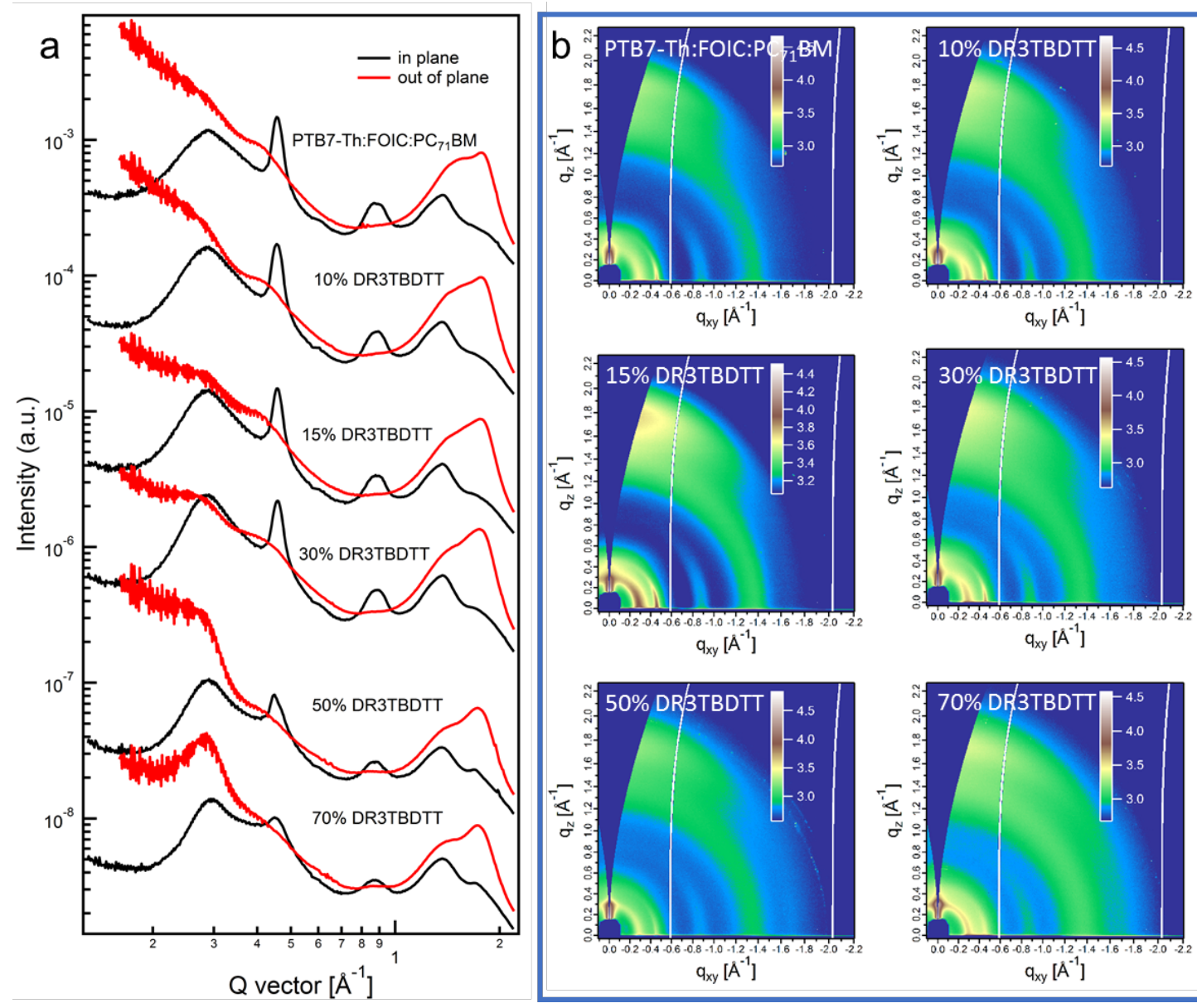

Figure S10. (a) The GIWAXS line curves and (b) 2D GIWAXS patterns of the quaternary blends with various DR3TBDTT ratios.
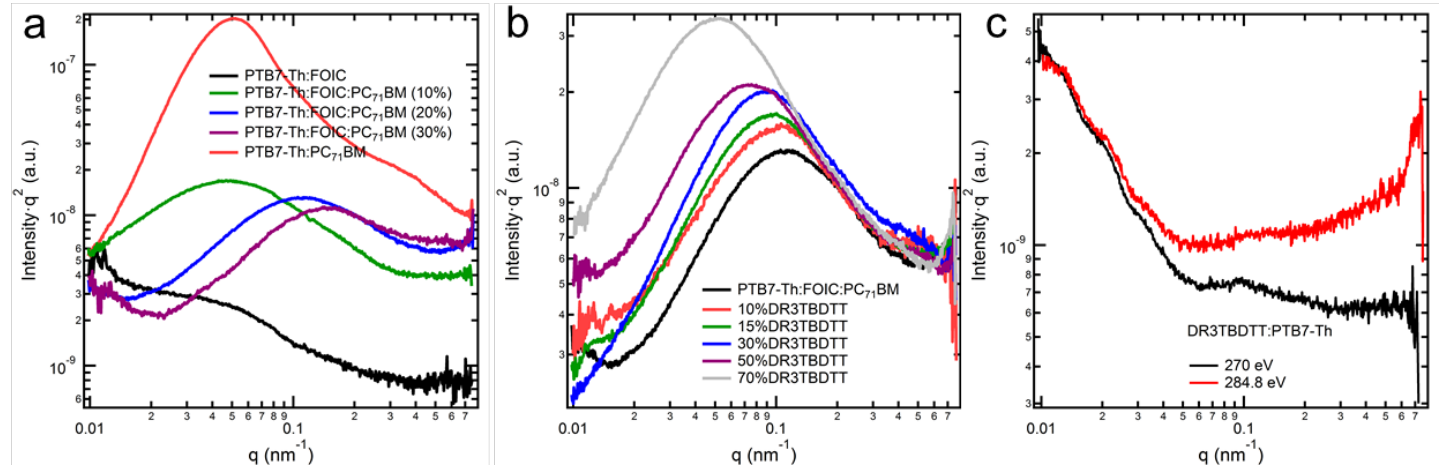

Figure S11. $(a, b)$ R-SoXS profiles obtained at $284.8 \mathrm{eV}$ of the ternary and quaternary blends with various PCBM and DR3TBDTT ratios. (c) The scattering curves of DR3TBDTT:PTB7-Th blend at X-ray energy of $270 \mathrm{eV}$ and $284.8 \mathrm{eV}$. The peaks 
located at $\sim 0.01$ and $\sim 0.1 \mathrm{~nm}^{-1}$ are caused by film mass thickness, rather than the morphological information.
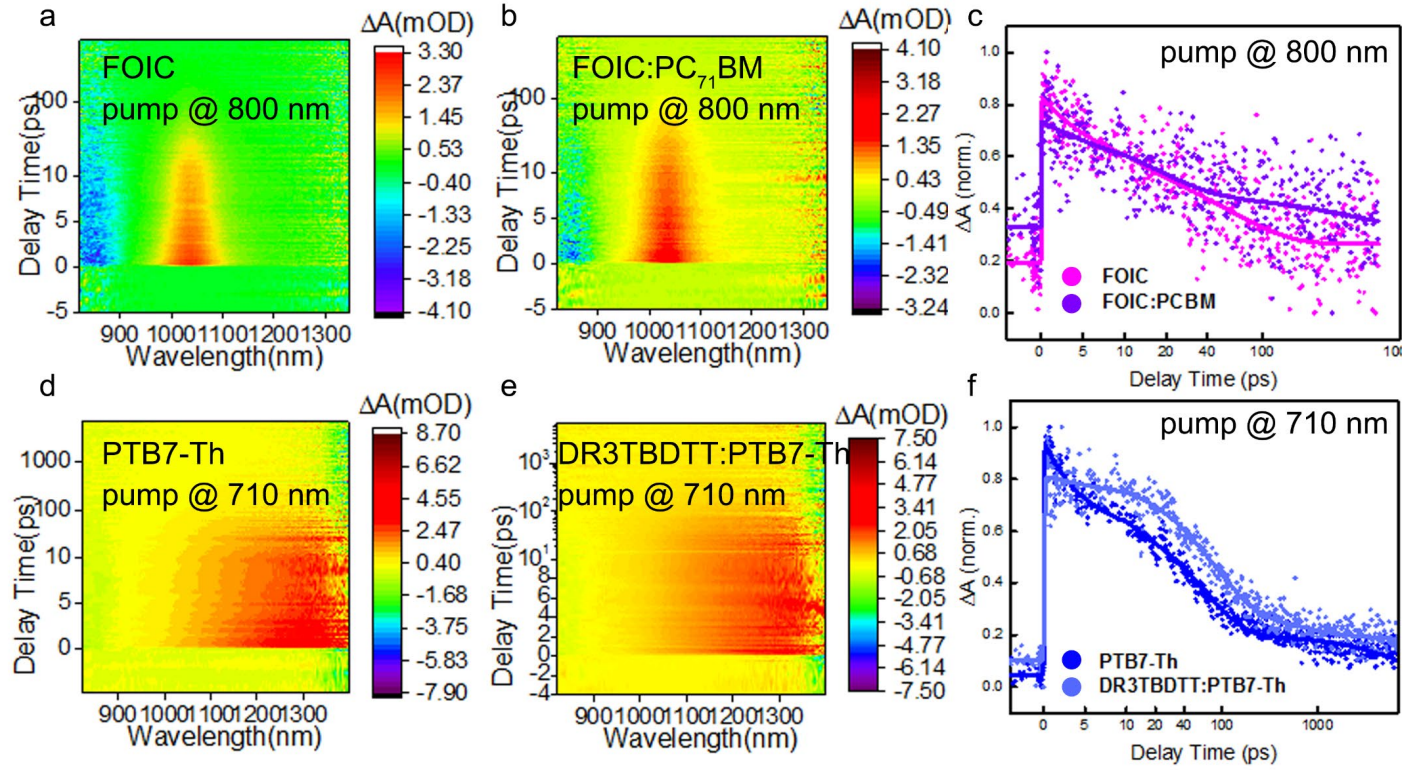

Figure S12. Transient absorption spectrograms of the neat FOIC, and FOIC:PCBM blend, neat PTB7-Th, DR3TBDTT:PTB7-Th blend films excited at $800 \mathrm{~nm}(\mathrm{a}-\mathrm{b})$ and $710 \mathrm{~nm}$ (d-e), respectively. The illustrated dynamics probing at $1160 \mathrm{~nm}$ with pump wavelength of $800 \mathrm{~nm}$ (c) and $710 \mathrm{~nm}$ (f), respectively.
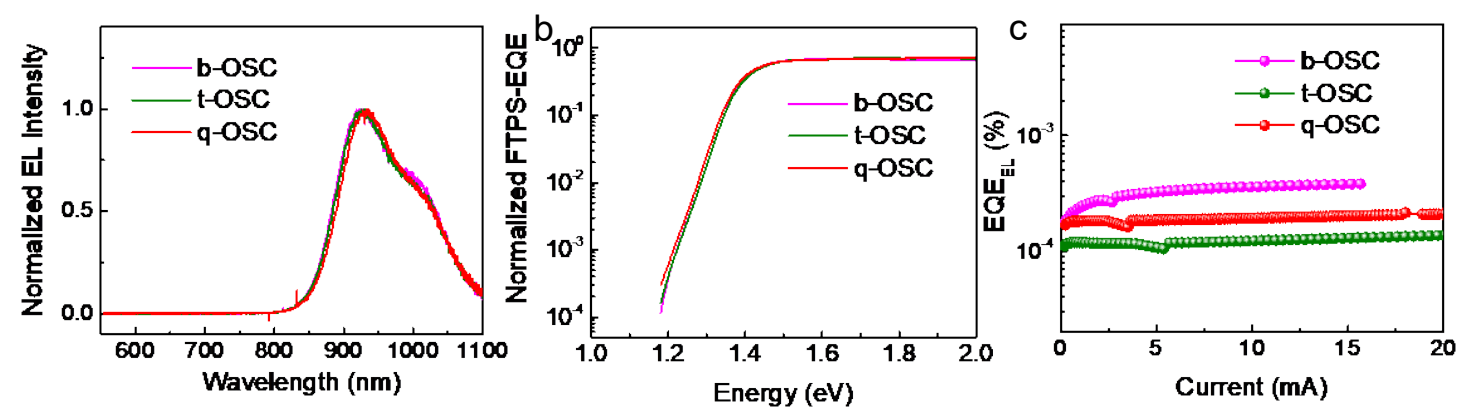

Figure S13. (a) Normalized electroluminescence spectra, (b) Normalized FTPS-EQE response, and (c) Normalized EQE $E_{E L}$ of the optimized binary, ternary, and quaternary devices. 

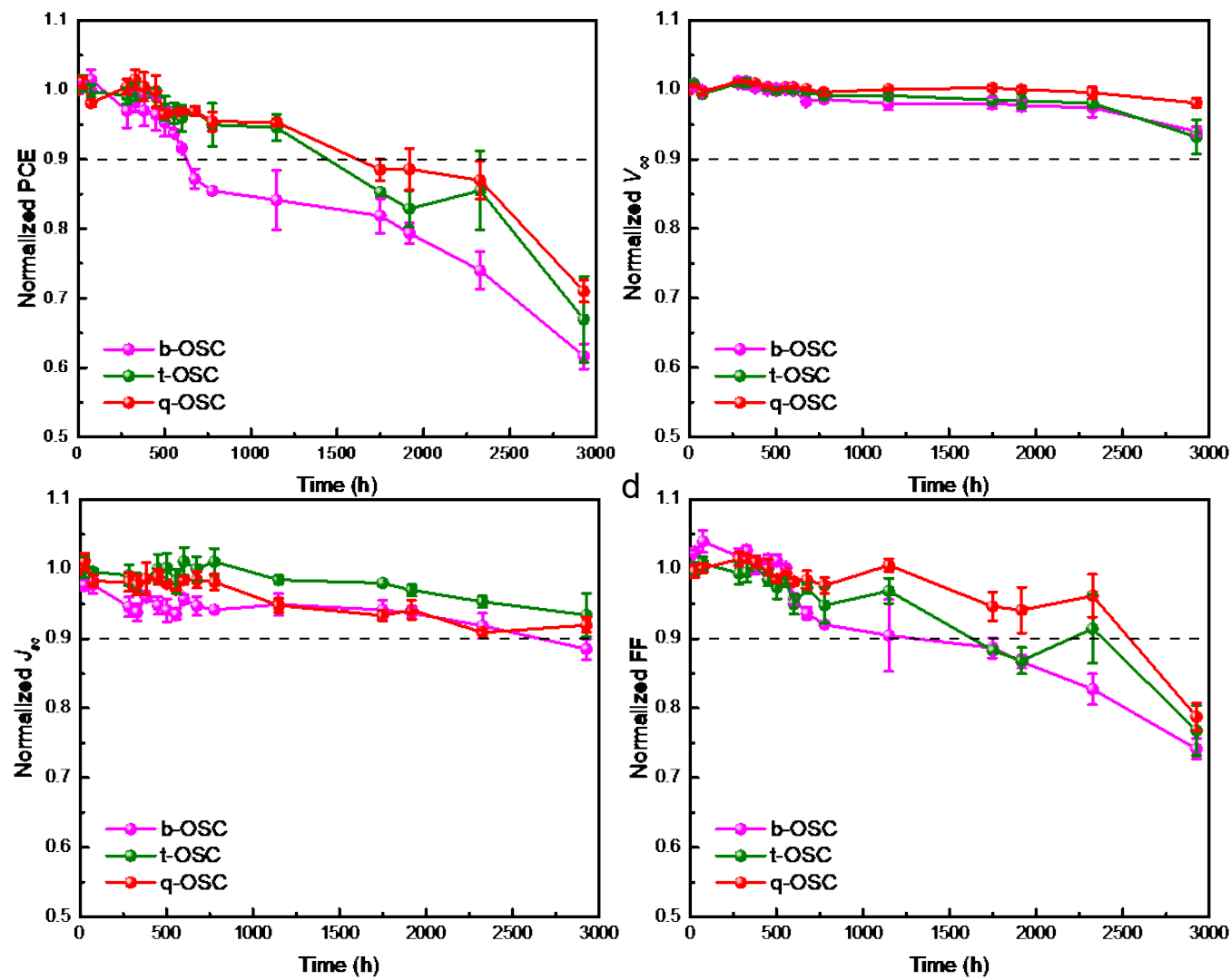

Figure S14. The photovoltaic parameter changes as a function of storage time in nitrogen glovebox at room temperature.

\subsection{Supplementary Table}

Table S1. Summarized photovoltaic parameters of the ternary devices. The average values and standard deviation were calculated from more than 15 cells.

\begin{tabular}{|l|l|l|l|l|}
\hline PCBM content & $\boldsymbol{V}_{\text {oc }}(\mathbf{V})$ & $\boldsymbol{J}_{\text {sc }}\left(\mathbf{m A ~ \mathbf { ~ c m } ^ { - 2 } )}\right.$ & FF (\%) & Efficiency (\%) \\
\hline $\mathbf{0 \%}$ & $0.74 \pm 0.01$ & $23.18 \pm 0.53$ & $65.62 \pm 1.08$ & $11.27 \pm 0.23(11.79)$ \\
\hline $\mathbf{1 0} \%$ & $0.74 \pm 0.01$ & $24.00 \pm 0.48$ & $66.83 \pm 0.79$ & $11.91 \pm 0.20(12.31)$ \\
\hline $\mathbf{2 0} \%$ & $0.74 \pm 0.01$ & $24.34 \pm 0.69$ & $67.49 \pm 1.07$ & $12.16 \pm 0.26(12.61)$ \\
\hline $\mathbf{3 0} \%$ & $0.74 \pm 0.01$ & $24.21 \pm 0.69$ & $65.72 \pm 0.89$ & $11.77 \pm 0.16(11.99)$ \\
\hline $\mathbf{5 0} \%$ & $0.75 \pm 0.01$ & $23.81 \pm 0.51$ & $61.81 \pm 0.83$ & $11.04 \pm 0.42(11.36)$ \\
\hline $\mathbf{7 0} \%$ & $0.77 \pm 0.01$ & $22.98 \pm 0.37$ & $60.85 \pm 0.84$ & $10.79 \pm 0.16(10.65)$ \\
\hline
\end{tabular}




\begin{tabular}{|l|l|l|l|l|}
\hline $\mathbf{9 0} \%$ & $0.79 \pm 0.01$ & $18.22 \pm 0.22$ & $52.00 \pm 0.87$ & $7.54 \pm 0.15(7.74)$ \\
\hline
\end{tabular}

Table S2. Summarized photovoltaic parameters of the quaternary devices. The average values and standard deviation were calculated from more than 15 cells.

\begin{tabular}{|l|l|l|l|l|}
\hline $\begin{array}{l}\text { DR3TBDTT } \\
\text { content }\end{array}$ & $\boldsymbol{V}_{\text {oc }}(\mathbf{V})$ & $J_{\text {sc }}\left(\mathbf{m A ~ c m}^{-2}\right)$ & FF (\%) & Efficiency (\%) \\
\hline $\mathbf{0 \%}$ & $0.74 \pm 0.01$ & $24.34 \pm 0.69$ & $67.49 \pm 1.07$ & $12.16 \pm 0.26(12.61)$ \\
\hline $\mathbf{1 0 \%}$ & $0.74 \pm 0.01$ & $25.01 \pm 0.56$ & $67.12 \pm 0.80$ & $12.47 \pm 0.34(13.14)$ \\
\hline $\mathbf{1 5 \%}$ & $0.75 \pm 0.01$ & $25.28 \pm 0.48$ & $69.52 \pm 0.78$ & $13.12 \pm 0.19(13.51)$ \\
\hline $\mathbf{2 0} \%$ & $0.75 \pm 0.01$ & $25.04 \pm 0.65$ & $66.38 \pm 0.61$ & $12.39 \pm 0.33(13.13)$ \\
\hline $\mathbf{3 0} \%$ & $0.75 \pm 0.01$ & $24.53 \pm 0.38$ & $68.34 \pm 0.84$ & $12.67 \pm 0.42(13.04)$ \\
\hline $\mathbf{5 0 \%}$ & $0.77 \pm 0.01$ & $22.41 \pm 0.61$ & $67.47 \pm 1.14$ & $11.71 \pm 0.21(11.95)$ \\
\hline
\end{tabular}

Table S3. The enthalpy change $(\Delta \mathrm{H})$ and corresponding crystallization peak centers of neat FOIC, b-, t-, and q- blends at the first heating round.

\begin{tabular}{|c|c|c|c|c|c|c|c|c|}
\hline \multicolumn{4}{|c|}{ FOIC } & \multicolumn{2}{c|}{ b-blend } & t-blend & \multicolumn{2}{c|}{ q-blend } \\
\hline$-0.19 \mathrm{~J} / \mathrm{g}$ & $-0.51 \mathrm{~J} / \mathrm{g}$ & $-3.76 \mathrm{~J} / \mathrm{g}$ & $-2.45 \mathrm{~J} / \mathrm{g}$ & $-0.96 \mathrm{~J} / \mathrm{g}$ & $-3.54 \mathrm{~J} / \mathrm{g}$ & $-0.69 \mathrm{~J} / \mathrm{g}$ & $-0.40 \mathrm{~J} / \mathrm{g}$ & $-0.34 \mathrm{~J} / \mathrm{g}$ \\
\hline $142.7^{\circ} \mathrm{C}$ & $165.1^{\circ} \mathrm{C}$ & $216.2^{\circ} \mathrm{C}$ & $251.6^{\circ} \mathrm{C}$ & $185.4^{\circ} \mathrm{C}$ & $233.1^{\circ} \mathrm{C}$ & $191.4^{\circ} \mathrm{C}$ & $188.2^{\circ} \mathrm{C}$ & $225.9^{\circ} \mathrm{C}$ \\
\hline
\end{tabular}

Table S4. Summarized GIWAXS fitting results of the quaternary blends.

\begin{tabular}{|c|c|c|c|c|c|c|c|c|}
\hline & \multicolumn{2}{|c|}{$001_{\text {FOIC }}$} & \multicolumn{2}{c|}{$100_{\text {FOIC }}$} & \multicolumn{2}{c|}{$100_{\text {PTB7-Th }}$} & \multicolumn{2}{c|}{$010_{\text {blend }}$} \\
\hline & $\begin{array}{c}\text { d-spacing } \\
(\AA)\end{array}$ & $\begin{array}{c}\mathrm{L}_{\mathrm{C}} \\
(\mathrm{nm})\end{array}$ & $\begin{array}{c}\text { d-spacing } \\
(\AA)\end{array}$ & $\begin{array}{c}\mathrm{L}_{\mathrm{C}} \\
(\mathrm{nm})\end{array}$ & $\begin{array}{c}\text { d-spacing } \\
(\AA)\end{array}$ & $\begin{array}{c}\mathrm{L}_{\mathrm{C}} \\
(\mathrm{nm})\end{array}$ & $\begin{array}{c}\text { d-spacing } \\
(\AA)\end{array}$ & $\begin{array}{c}\mathrm{L}_{\mathrm{C}} \\
(\mathrm{nm})\end{array}$ \\
\hline b-OSC & 21.9 & 7.5 & 13.7 & 19.5 & 23.5 & 5.5 & 4.2 & 2.15 \\
\hline t-OSC & 21.6 & 10.6 & 13.7 & 18.6 & 23.5 & 6.3 & 4.2 & 2.10 \\
\hline q-OSC & 21.6 & 9.0 & 13.7 & 18.1 & 23.5 & 7.2 & 4.2 & 2.02 \\
\hline
\end{tabular}

Table S5. Quantified life time of polarons of various blends excited at $800 \mathrm{~nm}$. 


\begin{tabular}{|l|c|c|c|c|}
\hline & $\mathrm{A}_{1}$ & $\mathrm{~A}_{2}$ & $\tau_{1}(\mathrm{ps})$ & $\tau_{2}(\mathrm{ps})$ \\
\hline b-blend & $-0.163 \pm 0.01$ & $0.175 \pm 0.009$ & $8.6 \pm 1.0$ & $97 \pm 10$ \\
\hline t-blend & $-0.153 \pm 0.007$ & $0.106 \pm 0.006$ & $12.6 \pm 1.3$ & $330 \pm 53$ \\
\hline q-blend & $-0.162 \pm 0.005$ & $0.120 \pm 0.008$ & $16.0 \pm 1.3$ & $2612 \pm 464$ \\
\hline
\end{tabular}

Table S6. Quantified life time of polarons of various blends excited at $710 \mathrm{~nm}$.

\begin{tabular}{|l|c|c|c|c|}
\hline & $\mathrm{A}_{1}$ & $\mathrm{~A}_{2}$ & $\tau_{1}(\mathrm{ps})$ & $\tau_{2}(\mathrm{ps})$ \\
\hline b-blend & $-0.059 \pm 0.005$ & $0.100 \pm 0.005$ & $7.6 \pm 1.6$ & $301 \pm 41$ \\
\hline t-blend & $-0.1323 \pm 0.009$ & $0.076 \pm 0.009$ & $10.2 \pm 1.5$ & $148 \pm 38$ \\
\hline q-blend & $-0.095 \pm 0$ & $0.169 \pm 0.013$ & $12.8 \pm 0$ & $2801 \pm 452$ \\
\hline
\end{tabular}

Table S7. Summarized parameters of binary, ternary, and quaternary solar cells.

\begin{tabular}{|c|c|c|c|c|c|c|c|c|c|c|}
\hline & $\begin{array}{c}E_{\text {gap }} \text { a) } \\
(\mathbf{e V})\end{array}$ & $\begin{array}{c}q V_{\text {oc }} \\
(\mathbf{e V})\end{array}$ & $\begin{array}{c}E_{\text {loss }} \\
(\mathbf{e V})\end{array}$ & $f\left(\mathrm{eV}^{2}\right)$ & $\lambda(\mathbf{e V})$ & $\begin{array}{c}E_{\mathrm{CT}} \\
(\mathbf{e V})\end{array}$ & $\begin{array}{c}\Delta E_{2} \\
(\mathbf{e V})\end{array}$ & $\begin{array}{c}\Delta E_{1} \\
(\mathbf{e V})\end{array}$ & $\begin{array}{c}\text { EQEEL } \\
(\%)\end{array}$ & $\begin{array}{c}\Delta E_{3} \\
(\mathbf{e V})\end{array}$ \\
\hline b-OSC & 1.47 & 0.73 & $\mathbf{0 . 7 4}$ & 0.005 & 0.08 & 1.30 & $\mathbf{0 . 1 7}$ & 0.22 & $2.50 \mathrm{E}-6$ & 0.33 \\
\hline t-OSC & 1.48 & 0.73 & $\mathbf{0 . 7 5}$ & 0.005 & 0.09 & 1.30 & $\mathbf{0 . 1 8}$ & 0.22 & $1.18 \mathrm{E}-6$ & 0.35 \\
\hline q-OSC & 1.47 & 0.74 & $\mathbf{0 . 7 3}$ & 0.02 & 0.13 & 1.33 & $\mathbf{0 . 1 4}$ & 0.25 & $1.81 \mathrm{E}-6$ & 0.34 \\
\hline
\end{tabular}

a) The $E_{\text {gap }}$ in this manuscript is determined by the crossing point of extrapolated line of the EQE edge and horizontal tangent of the local peak. 


\section{Refferences}

[1] T. Li, S. Dai, Z. Ke, L. Yang, J. Wang, C. Yan, W. Ma, X. Zhan, Adv. Mater., 30 (2018) 1705969.

[2] J.A. Bartelt, D. Lam, T.M. Burke, S.M. Sweetnam, M.D. McGehee, Adv. Energy Mater., 5 (2015) 1500577 .

[3] A. Wagenpfahl, D. Rauh, M. Binder, C. Deibel, V. Dyakonov, Physical Review B, 82 (2010) 115306.

[4] A. Hexemer, W. Bras, J. Glossinger, E. Schaible, E. Gann, R. Kirian, A. MacDowell, M. Church, B. Rude, H. Padmore, J. Phys.: Conf. Ser., 247 (2010) 012007.

[5] E. Gann, A.T. Young, B.A. Collins, H. Yan, J. Nasiatka, H.A. Padmore, H. Ade, A. Hexemer, C. Wang, Rev. Sci. Instrum., 83 (2012) 045110. 